\title{
LA BIBLIOTECA DE D. ANDRÉS DE MONDRAGÓN, I MARQUÉS DE SANTA CRUZ DE RIVADULLA, MECENAS Y POLÍTICO GALLEGO DEL SIGLO XVII (1645-1709)
}

\author{
Por \\ LEOPOLDO FERNÁNDEZ GASALLA
}

\begin{abstract}
Dentro de la moderna indagación en las fuentes documentales a la búsqueda de un más perfecto conocimiento del mundo de la difusión del libro y sus lectores, a la que instaba hace ya casi veinte años Chevalier $^{1}$, existen dos líneas de investigación bastante obvias. La primera y más tradicional ha sido la del análisis de las bibliotecas de los grandes personajes, o al menos de las de aquellos que las poseían más voluminosas. Una segunda vía intenta conseguir visiones de conjunto a través del estudio sistemático de fondos documentales, dedicando por la riqueza de información que nos proporcionan, una especial atención a los recuentos de bienes contenidos en los protocolos notariales. Apesar de la mayor antigüedad de la primera de ellas y de los esclarecedores resultados que se obtienen por vía de la segunda, a nuestro entender no debe arrinconarse el análisis pormenorizado de las bibliotecas considerables como destacadas, bien por el número de volúmenes que abarcaban, bien por la relevancia social de sus propietarios,
\end{abstract}

\footnotetext{
${ }^{1}$ CHEVALIER, Maxime: Lecturas y lectores en la España del siglo XVII. Madrid. 1976.

"CUADERNOS DE ESTUDIOS GALLEGOS", Tomo XLII, Fascículo 107, Santiago 1995.
} 
pues es aún mucho lo que a este ejercicio le resta por aportar al estudio de las mentalidades ${ }^{2}$.

Uno de los grupos sociales a los cuales se ha prestado mayor atención en Galicia durante los últimos años, en lo que a sus bibliotecas se refiere, ha sido el de los artistas y más concretamente el de los arquitectos que ejercieron su labor entre los siglos XVI y XVIII. Ello se debe tanto a la tarea de vaciado sistemático de los principales archivos, que nos ha permitido ir contando con la documentación apropiada, como al interés por conocer su preparación profesional y sus intereses intelectuales. Así, han visto la luz estudios sobre las bibliotecas de Domingo de Andrade y Fernando de Casas Novoa ${ }^{3}$, pero ya el propio Pérez Costanti en su Diccionario de artistas (1930) transcribía fragmentos de dos inventarios en los que se recogen los volúmenes que poseían respectivamente los escritores Juan Bautista Celma y Francisco de Moure ${ }^{4}$.

Con estas líneas que ahora presentamos, pretendemos ofrecer una pieza más que contribuya a completar el mosaico que haya de mostrar el deseado panorama, centrándonos en este caso en el estudio de los libros pertenecientes a un político y destacado aristócrata compostelano de la segunda mitad del siglo XVII, como es el caso de don Andrés de Mondragón.

La inmensa mayoría de los inventarios de bienes inclusos en los protocolos notariales gallegos en los que se recuentan libros, corresponden a eclesiásticos, especialmente a canónigos de las diferentes catedrales y colegiatas y, en menor medida, a otros miembros del clero secular. Ello es debido a su superior formación cultural, a su relativa eminencia en el conjunto de las poblaciones urbanas como Santiago, Lugo y Orense, y al he-

\footnotetext{
${ }^{2}$ En cuanto a la primera línea de indagación véanse GELABERT GONZÁLEZ, Juan Eloy: La cultura libresca en una ciudad de provincias del Renacimiento. I/ Coloquio de Metodología aplicada. vol. II. Santiago. Universidad de Santiago. 1984. pp. 147-153. y GARCÍA GONZÁLEZ, Fernando: As bibliotecas particulares no Ferrol do Antigo Réxime (1680-1835). Historia Nova II. Santiago. Asociación Galega de Historiadores. 1994. pp. 107-118.

${ }^{3}$ TAÍN GUZMÁN, Miguel: Comentarios a Excelencias, Antigüedad y Nobleza de la Arquitectura. Santiago. Xunta de Galicia. 1993. FOLGAR DE LA CALLE, M.C.: Un inventario de bienes de Fernando de Casas. Cuadernos de Estudios Gallegos. Santiago. 1982. Véase también nuestro trabajo: Las bibliotecas de los arquitectos gallegos en el siglo XVII: Los ejemplos de Francisco Dantas y Diego de Romay. Museo de Pontevedra. vol. XLIII [en prensa].

${ }^{4}$ PÉREZ COSTANTI, Pablo: Diccionario de artistas que florecieron en Galicia durante los siglos XVI y XVII. Santiago. Imprenta del Seminario. 1930. pp. 154 y 589.
}

"CUADERNOS DE ESTUDIOS GALLEGOS", Tomo XLII, Fascículo 107, Santiago 1995. 
cho de que, debido a su particular situación jurídica, se hacía preciso la realización de estos inventarios postmortem. Por lo que respecta al estamento nobiliar, tan sólo se recurría a esta medida en el caso de que la sucesión del difunto pudiese ser objeto de pleitos o este hubiese fallecido ab intestato, caso por otra parte muy poco frecuente. Así pues, a esto atribuimos en buena parte la circunstancia de que no haber localizado entre la documentación otros inventarios de bienes de aristócratas distinguidos de Santiago ${ }^{5}$, así como a las circunstancias de ser un grupo reducido y con un nivel cultural medio menor, propio de quien no recibe de las letras - sacras o profanas- el acceso a su estado. A través de los protocolos notariales de la ciudad de La Coruña conocemos suficientes ejemplos de bibliotecas pertenecientes a oidores de la Real Audiencia de Galicia como para afirmar que, incluso los tan habituales títulos devotos ocupaban un reducidísimo espacio en ellas ${ }^{6}$, pues estaban compuestas en su práctica totalidad por obras de carácter jurídico, siendo así que podríamos asegurar que también por variedad de temas e intereses el caso que nos ocupa es infrecuente. La singularidad de su existencia es por lo tanto, el primer motivo que nos condujo a profundizar en el estudio de este documento, pero mayor peso tuvo aún en esta decisión el volumen y la calidad de las obras enumeradas. La lectura de los títulos colabora en buena medida a definir el perfil intelectual y humano no sólo del propio marqués, sino también de los personajes que le precedieron como cabezas de la familia Mondragón. Si bien el atribuir tajantemente la propiedad o adquisición de tal o cual volumen a uno de ellos sería una pretensión vana, si que resulta esclarecedor la comprobación de la existencia de publicaciones no reeditadas más alla del siglo XVI o de la fecha de nacimiento de este primer marqués de Santa Cruz de Rivadulla.

\footnotetext{
${ }^{5}$ Nuestra afirmación se refiere a la documentación notarial del distrito de Santiago conservada en el AHUS de los años 1649 a 1712 . De lo dicho valga como ejemplo el caso del conde de Priegue, de quien conservamos su testamento, fechado en 1671, pero de cuyos bienes no nos consta que se hiciese recuento alguno. A.H.U.S. Protocolos del distrito de Santiago. $n^{\circ} 2027$. fol. 385. esc.: Bugallo Salmonte, Domingo.

${ }^{6}$ Entre otros vid. AICNC. Protocolos del distrito de La Coruña, ${ }^{\circ}{ }^{\circ}$ 1032. fol. 66. esc.: Fandiño y Ocampo, Benito (1655). Recuento de los bienes del oidor don Gregorio Álvarez de Castro, y ${ }^{\circ}$ 8578. fol. s.n. (1670). Recuento de bienes del doctor don Juan Bautista Gravo de Moscoso.
}

"CUADERNOS DE ESTUDIOS GALLEGOS", Tomo XLII, Fascículo 107, Santiago 1995. 


\section{LA FAMILIA MONDRAGÓN}

En las personas de dos canónigos, uno de Santiago y otro de Tui, la familia Mondragón se asienta en Compostela a finales del siglo XV - por lo tanto en el mismo inicio de la Edad Moderna - procedente de la villa guipuzcoana del mismo nombre que adoptaron como apellido, sobreponiéndolo al de Eremuzqueta, topónimo de su primitivo solar.

La solvencia económica procedente del ejercicio de sus cargos les permitió la incorporación al proceso de adquisición de propiedades rurales en el que se hallaba inmerso a comienzos del siglo XVI una amalgama de canónigos, regidores, escribanos y mercaderes, que conformaban las clases medias urbanas gallegas. De esta manera llegan a enraizar con firmeza en las tierras de la Ulloa, pero también en las del Deza, Morrazo y Tabeirós.

Paralelo a su ascenso social y económico discurrió el aumento de su patrimonio artístico. Las principales manifestaciones externas de ello fueron el progresivo engrandecimiento del centro de sus propiedades agrícolas en la Ulla, el pazo de Ortigueira en Santa Cruz de Rivadulla, su palacio de la Rúa Nova en Santiago y la capilla de la Piedad de la catedral. Del estudio de su papel como comitentes de obras de arte nos hemos ocupado en otro lugar ${ }^{7}$, por lo que recordaremos tan sólo el hecho de que en cada momento acudieran a los mejores especialistas de cada disciplina dentro de la ciudad de Santiago y que aún recurriesen a artistas foráneos cuando su exigente gusto no se veía satisfecho. Así trabajaron para ellos los escultores Miguel Perrín, Juan Bautista Celma y Mateo de Prado, los arquitectos Jácome García, Diego de Romay y Domingo de Andrade.

Aunque carecemos de una cronología exacta de cómo se produjo la sucesión de los cabezas de familia de los Mondragón desde su asentamiento en Compostela hasta llegar a la figura de don Andrés, I Marqués de Santa Cruz de Rivadulla, si conocemos con precisión el nombre de las

${ }^{7}$ FERNÁNDEZ GASALLA, Leopoldo: El mecenazgo de la familia Mondragón. El pazo de Santa Cruz de Rivadulla. Abrente, La Coruña, 1991-92. n 23-24. Sobre el patrocinio artístico de los Mondragón véase también RÍOS MIRAMONTES, María Teresa: Estudio histórico artístico de la iglesia del Divino Salvador de Coiro. Patronazgo de los Mondragón, marqueses de Santa Cruz de Rivadulla. Estudios de Historia del Arte en honor del profesor Dr. D. Ramón Otero Túnez. Santiago. Universidad de Santiago, 1993. pp. 251-276. Ya en relación con los Armada, sus herederos desde 1709, vid. CARRO GARCÍA, A.J.: Fachada principal del palacio del Marqués de Santa Cruz de Santiago. Cuadernos de Estudios Gallegos. 1964. p. 320.

"CUADERNOS DE ESTUDIOS GALLEGOS", Tomo XLII, Fascículo 107, Santiago 1995. 
personas que ostentaron el patronazgo de la capilla de la Piedad durante ese tiempo, título consustancial al ejercicio de la jefatura familiar. La capilla catedralicia, como todas las de este tiempo, además de ser una entidad religiosa, lo era también económica, siendo así que la brillantez y frecuencia del culto que en ella se celebrase, dependía como es lógico de lo saneado de sus rentas. Cuando en 1521 el canónigo don Juan de Mondragón contrató la construcción del recinto, su nivel de ingresos debía de ser excelente a juzgar por la rapidez con que se concluyó y se le dotó de la reja y retablo, pues en 1526 el conjunto estaba ya finalizado. Y, de hecho, en documentación conservada en el Archivo del Reino de Galicia se nos explica como

«fundo y adefico y doto la dicha ymaxen de Nuestra Señora de la Piedad a su costa, con gran gasto de su azienda y la enrrequesio de muchos vienes muebles y rraices, ynstituyendo en ella seis capellanes, un sacristan clerigo, dos acolitos y otros ministros para que se aumentase el culto devino y fuese Nuestro Señor mas vien servido.» ${ }^{8}$

En 1531 recibió su fundación confirmación por bula de Clemente VII. Fallecido en 1540, le sucedió en la jefatura familiar el cardenal don Juan de Mondragón, quien la ejerció al menos hasta $1576^{9}$, siendo en estos años cuando se hicieron importantes reformas en su palacio de la Rúa Nova ${ }^{10}$. Sabemos por el mismo documento que continuó con el rumbo trazado por su predecesor, puesto que

« [...] dono [a la capilla] y a los mas patronos que le sucediesen muchos vienes y rrentas en los partidos de Desa, Taveiros, Baños, Vea, Morraso

\footnotetext{
${ }^{8}$ A.R.G. Real Audiencia. Leg $^{\circ}$ 16.511. $\mathrm{n}^{\circ}$ 59. fol. 23-24. Sobre la dotación de la capilla, véase también CRESPO DEL POZO, Fray José de Santiago: Blasones y linajes de Galicia. Tomo II. pp. 312-313.

${ }^{9}$ PÉREZ COSTANTI, Pablo: Diccionario de artistas que florecieron en Galicia durante los siglos XVI y XVII. Santiago. Imprenta del Seminario. 1930. p. 527. En ese año aparece contratando la restauración de la bóveda de la capilla mayor de las iglesias de San Julián de Marín y San Salvador de Coiro, que eran de su patronazgo, con el maestro Sebastián de la Tijera.

${ }^{10}$ En 1552 don Juan de Mondragón recibió licencia para reedificar este palacio. Vid. ANEIROS RODRÍGUEZ, R.M.: Aportación documental sobre la actividad artística compostelana entre 1550 y 1570. Universidad de Santiago. 1990. Tesis de licenciatura inédita. fol. 8.
}

"CUADERNOS DE ESTUDIOS GALLEGOS", Tomo XLII, Fascículo 107, Santiago 1995. 
y otras partes. Y de nuebo eñadio otros dos capellanes para que el uno dijese misa una semana y el otro la otra y se dijese una misa cantada todos los días en dicha capilla, la qual y las demas se diesen a oras fijas y senaladas como son al alva, a la prima, a las nuebe y a las onze y, en berano, a las diez, ubiese perpetuamente quatro misas y a los biernes cinco, la qual tiene obligacion de dicir el secristan de dicha capilla»».

Muerto el cardenal en fecha que hoy por hoy nos es desconocida, los patronos de la capilla pasaron a ser el canónigo don Pedro de Mondragón, primero, y el racionero don Juan de Mondragón, último de los cuatro clérigos que presidieron esta estirpe durante el siglo XVI. Con la llegada del nuevo siglo, aparecen los hermanos Mateo y Martín de Mondragón haciéndose cargo del patronazgo, sin que ninguno de los dos reciba el tratamiento de don, a pesar de la condición de clérigo del segundo, rector del beneficio de San Salvador de Coiro y residente en Madrid a la altura de $1613^{11}$. El mayor de los hijos de Mateo, don Antonio, heredero del mayorazgo, falleció sin sucesor de forma que sus derechos pasaron a su hermano don Juan, primero de una serie de tres Mondragones del mismo nombre que hasta 1663 encabezaron la familia. Fue el segundo don Juan, llamado el viejo, quien casó con doña Isabel Abraldes Teijeiro, enlazando así ambas fami$\operatorname{lias}^{12}$. Con su vástago, don Juan de Mondragón y Eremuzqueta, la familia ganó terreno en el campo de la vida pública compostelana, pues tras acumular honores en su persona, dejó a su hijo don Andrés en la antesala de la nobleza titulada. De entrada heredó de su madre el señorío jurisdiccional de Santa Cruz de Rivadulla, pues con anterioridad no estaba unido al pazo de Ortigueira, sino que pertenecía a los Abraldes, señores del pazo de Guimaráns ${ }^{13}$. A través de las Actas Municipales del ayuntamiento de Santiago, conocemos algunos detalles de su carrera política. El 1 de octubre de 1649 se registra su toma de posesión como regidor - lo que le aupaba entre la oligarquía local — y ya en 1653 lo hallamos ejerciendo como diputado

\footnotetext{
${ }^{11}$ RÍOS MIRAMONTES, Op. cit., p. 258.

${ }^{12}$ Sobre la familia Abraldes, su parentesco con la Mondragón y sus posesiones en la comarca de la Ulla, véase CRESPO DEL POZO, Op. cit. Tomo II. pp. 10-14. Diremos, no obstante, que se trataba de una dinastía patricia de cambiadores y comerciantes santiagueses enriquecidos y ennoblecidos asentados por matrimonio en la Ulla desde el siglo XIV.

${ }^{13}$ CRESPO DEL POZO, Op. cit. tomo II. pp. 312-313.
} 
del reino en Madrid ${ }^{14}$. Fue esta una situación que no hizo más que confirmar su nombramiento como familiar del Santo Oficio nueve años más tar$\mathrm{de}^{15}$. A estos dos títulos han de añadirse los de caballero de Santiago ${ }^{16}$ y de capitán de milicias que, como los anteriores, no sólo proporcionaban prestigio, sino que reportaban notables ventajas fiscales y, por descontado, proximidad a los centros de poder. Buena prueba de su emergencia social es el que el cronista fray Felipe de la Gándara le mencione en dos ocasiones: la primera en su recuento de los linajes ilustres del reino de Galicia, en el que aparece junto a su hermano don Gaspar, colegial mayor en Salamanca ${ }^{17}$ y la segunda al enumerar a los caballeros participantes en las acciones militares de 1658 en torno a la plaza de Monção, con motivo de la guerra de secesión portuguesa ${ }^{18}$. Muerto el 4 de mayo de 1663 en Santa Cruz de Rivadulla, su cadáver se trasladó por la noche hasta Santiago, siendo sepultado el 5 en la capilla de la Piedad ${ }^{19}$. Su hijo don Andrés, le sucedió en el puesto de regidor municipal el 15 de marzo del año siguiente ${ }^{20}$.

${ }^{14}$ A.H.U.S. Sección Concello de Santiago. Libro de consistorios municipales de 164849. fol. 210. En el ayuntamiento de 4 de septiembre del mismo año don Juan había presentado solicitud para ejercer el cargo por cesión del regidor Domingo González de Riazos, quien a su vez parece que ostentaba el cargo por presentación de don Antonio Albite Ozores de Sotomayor, el cual a juzgar por sus apellidos, debía de estar emparentado con la esposa de don Juan. Por otra parte sus primos los Abraldes venían siendo regidores de Santiago desde mediados del siglo XIV.

La noticia de su diputación aparece en A.H.M.C. Acuerdos municipales. Libro de ayuntamientos de 1653. fol. 28. Ayuntamiento de 1 de abril.

${ }^{15}$ Idem. de 1658. fol. 154.4 de septiembre.

${ }^{16}$ El hábito de Santiago lo obtuvo por cesión de su primo hermano el capitán don Pedro Abraldes de Quirós. A.H.U.S. Protocolos del distrito de Santiago. $n^{\circ} 1779$. fol. 642. esc.: Vidal de Lamas, Juan. «Scritura del capitan don Juan de Mondragon a fabor del capitan don Pedro Abraldes de Quiros» 1655-agosto-8.

${ }^{17}$ GÁNDARA, fray Felipe de la: Armas y Triunfos de los Hijos de Galicia. Santiago. Bibliófilos gallegos, 1970. Ed. facsímil. p. 510. «Proceden los Teixeiros de Santiago, Don Juan de Mondragon, Teixeiro, señor de la casa i Maiorazgo de los Mondragones desta ciudad, i Patron de su Capilla, i su hermano Don Gaspar de Mondragon, Abraldez, i Teixeiro, Colegial del Colegio del Arçobispo en Salamanca, i otros hermanos i hermanas, suias.).

${ }_{18}$ idem. p. 639.

${ }^{19}$ A.D.S. Parroquia de Sta. Ma Salomé. Libros sacramentales. $n^{\circ} 2$. (1642-1687). fol. 352. Contaría apenas cuarenta y dos años, pues según CRESPO DEL POZO (Op. cit. vol. III. p. 313) había nacido en 1621.

${ }^{20}$ A.H.U.S. Sección Concello de Santiago. Libro de consistorios municipales de 1664. fol. 117. Don Andrés había nacido en 1645, siendo bautizado el 19 de agosto de ese año. A.D.S. Parroquia de Sta. Ma Salomé. Libros sacramentales. $n^{\circ} 2$. (1642-1687).

"CUADERNOS DE ESTUdIOS GALLEGOS", Tomo XLII, Fascículo 107, Santiago 1995. 
En 1670 fue ordenado caballero de Santiago, recibiendo en 1681 el título de marqués de Santa Cruz de Rivadulla, con el vizcondado previo de San Julián de Piñeiro ${ }^{21}$. Durante estos años del último tercio del siglo, ejerce, como hiciera su padre, las funciones de diputado por Santiago en la Junta del Reino de Galicia y de representante de esta en Madrid. Probablemente fue en el curso de esos viajes cuando entró en relación con los Enríquez de Cabrera, que a la par de ostentar el título de almirantes de Castilla y duques de Medina de Río Seco, se hallaban inmersos de lleno en los tiras y aflojas de los partidos cortesanos del Madrid de Carlos II. Casado por poderes en 1691 con la hermana del último almirante ${ }^{22}$, esta alianza debió facilitar el que en 1696 le fuera concedido el empleo de corregidor y capitán de a guerra de la ciudad de Plasencia, en el que continuó hasta $1699^{23}$. La caída en desgracia de su cuñado en 1702 , con motivo de su deserción a favor del bando del archiduque Carlos, no parece haberle perjudicado abiertamente, pero le privó de un importante valedor en los círculos cortesanos. En 1704, nombrado diputado general del Reino por el ayuntamiento de Santiago con el objeto de jurar fidelidad a Felipe V, no llegó a ejercer dicho cargo por ciertas discrepancias que al respecto existieron con la ciudad de La Coruña ${ }^{24}$.

Tras su muerte el 26 de octubre de 1709 se efectuó inventario de sus bienes a través del cual conocemos los volúmenes que le pertenecían ${ }^{25}$.

${ }^{21}$ CRESPO POZO, Op. cit. vol. III. pp. 311-313.

${ }^{22}$ A.H.U.S. Protocolos del distrito de Santiago. $n^{\circ} 2757$. fol. 13. esc.: Villar, Domingo. 1691-diciembre-6. En junio de este mismo año se produjo la salida del conde de Oropesa del gobierno, siendo relevado por un Consejo de Estado en el que figuraba el conde Melgar, hijo de don Juan Tomás Enríquez de Cabrera, que desde septiembre ostentaría el título de almirante por muerte de su padre. A pesar de esta preminencia social, la casa de los duques de Medina de Rioseco se hallaba en un estado financiero pésimo, al contrario de lo que ocurría con la de la del marqués de Santa Cruz, de modo que pudo ser este un aliciente más a la hora de concertar el matrimonio. Sobre los duques de Medina de Rioseco vid. KAMEN, Henry: La España de Carlos II. Barcelona. Crítica. 1987. pp. 395-396 y $589-589$.

${ }^{23}$ A.H.U.S. Sección Concello de Santiago. Libro de consistorios municipales de 1696. fol. 271.

${ }^{24}$ A.H.U.S. Sección Concello de Santiago. Libro de consistorios municipales de 1704. fol. 499.

${ }^{25}$ A.H.U.S. Protocolos del distrito de Santiago. $n^{\circ} 2838$. fol. 45-52. esc.: López Raposo, Juan. 1710-abril-17. El recuento de libros ocupa los folios 49 al 52.

"CUADERNOS DE ESTUDIOS GALLEGOS", Tomo XLII, Fascículo 107, Santiago 1995. 


\section{LA BIBLIOTECA}

El punto de partida para el análisis de la biblioteca de don Andrés de Mondragón, es el recuento de los objetos que se conservaban en su residencia de Santiago, por lo que inmediatamente surge la pregunta de cuantos volúmenes tendría en ese momento depositados en el pazo de Ortigueira, sin que por el momento dispongamos de una respuesta, lo que hace que nuestro conocimiento del bagaje personal de nuestro hombre resulte mutilado.

Como es típico en esta clase de documentos, la imprecisión a la hora de efectuar la transcripción de los títulos es mayúscula, faltando en muchas ocasiones los nombres de los autores que, cuando si aparecen, lo hacen a menudo deformados o citados por el segundo apellido. En otros casos se nos da el nombre del autor, señalando únicamente el número de tomos. La falta de fidelidad a los encabezamientos originales llega al extremo de no respetarse siquiera el idioma en que se hallan escritos ${ }^{26}$. Todo ello dificulta una certera identificación de las obras, siendo en ocasiones absolutamente imposible ${ }^{27}$. La ausencia de un orden temático nos priva asimismo de un punto de apoyo pues, de haber existido, habría sido esencial, ya que el contexto nos permitiría tal vez desentrañar la naturaleza de las veinticuatro obras que hay que restar a los ciento noventa y seis títulos de la biblioteca, o confirmar algunas conjeturas sobre las que hemos tenido que cimentar nuestras conclusiones.

${ }^{26}$ El ejemplo más claro de esto lo tenemos en el asiento número ciento cuarenta y nueve, citado como «Diego Estuniga. Sobre las eregias», lo que nos demuestra como el escribano ha realizado una traducción por cuenta propia, pasando de latín a castellano el título del libro y el nombre del autor, pero se le escapa el apellido, que era Zúñiga. La misma sospecha la tenemos respecto a algunos ejemplares en portugués, pues son citados en castellano, sin que nos conste que haya existido edición en español.

${ }^{27}$ Estas dificultades son consustanciales a esta clase de documento, como ya lo reseñó en su momento Bartolomé Benassar: Los inventarios post-mortem y la Historia de las mentalidades. II Coloquio de Metodologia aplicada. vol. II. Santiago. Universidad de Santiago, 1984. p. 141

Con todo, dado que es muy posible que alguien más entendido y afortunado que nosotros llegue a localizar aquellas ante las que nos hemos rendido, incluimos en cada caso el fragmento original del inventario acompañado por el número de orden con el que aparecen en el documento. Especialmente esperanzadores son los progresos en el campo informático, de modo que cuando estén a disposición de los investigadores bancos de datos en los que se recojan los contenidos de los textos de catalogación bibliográfica fundamentales, la identificación se volverá indudablemente más sencilla.

"CUADERNOS DE ESTUDIOS GALLEGOS", Tomo XLII, Fascículo 107, Santiago 1995. 
Dejando ya los preámbulos, el primero de los grupos de obras en que dividiremos su biblioteca es el que hace referencia a la propia razón de ser del estamento social al que pertenecía el marqués, esto es, las que se ocupan de asuntos genealógicos y nobiliarios, pudiendo distinguirse las que tratan de familias de estirpe galaica de las que lo hacen en un ámbito peninsular. Así entre las primeras se cuentan

(132) «Pellicer, informe de la cassa de los Sarmientos»

PELLICER DE SALAS Y TOBAR, José: Informe del origen, antiguedad, calidad i sucession de la excelentisima Casa de Sarmiento de Villamayor y las unidas a ella por casamiento. Madrid. Sin impresor, 1663.

(168) «Saavedra. Ynsercion genealogica».

SAAVEDRA RIVADENEIRA, Fernando: Memorial de inserciones genealogicas tocantes a la casa y mas antiguo solar de Saavedra. Granada. Francisco Ochoa, $1674^{28}$.

mientras que estas otras ampliarían el horizonte,

(156) «Nobiliario de Aro»

LOPEZ DE HARO, Alonso: Nobiliario genealogico de los Reyes y Titulos de España. Dirigido a la Magestad del Rey Don Felipe Quarto nuestro señor. Compuesto por... criado de su Magestad, y Ministro en su Real Consejo de las Ordenes. Madrid. Viuda de Fernando Correa Montenegro. 1622. (2 vols. $)^{29}$.

(157) «Alarcon. Relacion genealogica».

SUAREZ DE ALARCON, Antonio: Relaciones genealogicas de los Marqueses de Trocifal, Condes de Torres Vedras... Escribiolas...

\footnotetext{
${ }^{28}$ Aunque en nuestro caso preferimos esta versión por el parecido del título al asiento del inventario, fue más corrientemente editada con el título de: Memorial al Rey Nuestro Señor en que se recopila, adiciona y representa quanto los cronistas y autores han escrito y consta por instrumentos del origen y antiguedad, descendencia,... de la casa de Saavedra y estados del Reino de Galicia. Granada. Francisco Ochoa, 1674. vid. PALAU DULCET, A.: Manual del librero hispanoamericano. Barcelona, 1950. vol. VI. p. 363.

${ }^{29}$ Vid PÉREZ PASTOR, Cristóbal: Bibliografia madrileña. Madrid. Imprenta de los huérfanos, 1891. n 1857. vol. III. p. 93.
}

"CUADERNOS DE ESTUDIOS GALLEGOS", Tomo XLII, Fascículo 107, Santiago 1995. 
primogenito de esta casa. Madrid. Diego Díaz de la Carrera, $1656^{30}$. (65) «Obras de Salazar en dos tomos»

SALAZAR Y CASTRO, Luis: Historia genealogica de la casa de Silva. Madrid. Melchor Alvarez y Mateo Llanos. 1685. (2 vols.) ${ }^{31}$.

Además de al nacimiento, la segunda condición a la que el marqués daba gran valor era la de caballero de Santiago, como lo demuestra las cruces del apóstol que hizo esculpir en el coronamiento de la fuente monumental de su pazo de Ortigueira. Habiéndolo sido también su padre, no es pues de extrañar la presencia de un volúmen con este tema

(141) «Establecimiento del horden de Santiago»

MEDRANO, García de: La regla y establecimiento de la cavalleria de Santiago de la Espada. Con la Historia del Origen y principio della. Valladolid. Luis Sanchez, $1603^{32}$.

o tal vez

VERGARA Y ALABA, Francisco de: Regla y establecimiento, de la Orden y Cavalleria del gloriosso apostol Santiago, patron de las Spañas, con la historia del origen y principio de ella. Madrid. Domingo Garcia Morras, 1655.

y también uno sobre las órdenes militares en general que no hemos identificado:

(150) «Origen de las ordenes militares» ${ }^{33}$.

${ }^{30}$ SIMÓN DÍAZ, José: Impresos del siglo XVII. Madrid, 1972. n 3423. p. 795. De todas formas, el estar la casa de Torres Vedras emparentada con la familia de los Abraldes (CRESPO POZO, op. cit. vol. II. p. 10) y estos a su vez con los Mondragón, es explicación suficiente para la presencia de este libro.

${ }^{31}$ Hay varios autores con este apellido y obras editadas en dos volúmenes, pero teniendo en cuenta los intereses de don Andrés, este nos ha parecido el más probable. El genealogista Luis de Salazar y Castro (1658-1734), publicó también en dos volúmenes antes de 1709, Alegaciones juridicas a favor de las Ordenes militares. s.a.s. imp.

${ }^{32}$ SIMÓN. Op. cit. $\mathrm{n}^{\circ} 616$. p. 138.

${ }^{33} \mathrm{Ni}$ el auto de circunstancia Las ordenes militares de Calderón de la Barca, ni la obra de Rades y Andrada Cronica de las tres ordenes militares. Toledo. Juan de Ayala, 1572 nos parece que sean el libro en cuestión.

"CUADERNOS DE ESTUDIOS GALLEGOS", Tomo XLII, Fascículo 107, Santiago 1995. 
En un caballero de Santiago la pericia en las artes de la milicia era poco menos que inexcusable; el más popular de los tratadístas especializados en el uso de las armas del siglo XVII español, Pacheco de Narváez, escribió varias obras que podrían encajar por su título con la referencia del inventario.

(36) «Narvaes. De las armas»

PACHECO DE NARVAEZ, Luis: Modo facil y nuevo para examinarse los maestros en la destreza de las armas y entender sus cien conclusiones o formas de saber. Madrid. Luis Sánchez, $1625^{34}$.

Ilustrado en esta doble vertiente de noble y caballero, para alguien que como don Andrés aspirase a hacer carrera en la política, era necesario estar al tanto de los escenarios én los que se desarrollaban los acontecimientos del gran mundo. Tal y como hoy ocurre, los libros de viajes suplían la falta de conocimiento directo e informaban al lector a cerca de la geografía física y humana; pero acaso debiéramos de empezar por una obra que explica el modo de llegar a muchos de esos lugares

(176) «Medina: Arte de nabegar»

MEDINA, Pedro de: Arte de navegar en que se contienen todas las reglas. Declaraciones, secretos y Avisos que a la buena navegacion son necesarios y se deben saber. Valladolid. Francisco Fernández de Córdoba, $1545^{35}$.

La náutica fue objeto de interés no sólo de los prácticos en la materia, sino de muchas otras personas, entre las que podemos señalar a varios artístas que trabajaron en Galicia o en la corte, como Francisco Dantas o Velázquez, probablemente por el considerable contenido matemático que incluían $^{36}$.

${ }^{34}$ Véase PALAU DULCET, Op. cit. vol. VI. p. 7. Otro posible título sería Nueva ciencia y filosofia de la destreza de las armas, su teorica y practica. Madrid. Melchor Sánchez, 1672.

${ }^{35}$ PALAU. Op. cit. vol. V. p. 121.

${ }^{36}$ FERNÁNDEZ GASALLA. Op. cit. y SÁNCHEZ CANTÓN, Francisco Javier: Los libros españoles que poseyó Velázquez. Varia velazqueña. Madrid, 1964.

"CUADERNOS DE ESTUdios GALLEGOS", Tomo XLII, Fascículo 107, Santiago 1995. 
Del mismo autor eran las Grandezas de España

(5) «Grandes de España de Medina»

MEDINA, Pedro de: Libro de grandezas y cosas memorables de Espa$\tilde{n} a$. Sevilla. Domingo de Robertis, $1549^{37}$.

que se completaban con los siguientes ejemplares

(74a) «Asia y (74b) Europa de Faria en seis thomos»

FARIA Y SOUSA, Manuel de: Asia Portuguesa. Lisboa. Valente de Oliveira y Craesbeck de Mello, 1666-1674. (3 vols.).

- Europa Portuguesa. Segunda edición correcta, ilustrada y añadida en tantos lugares y con tales ventajas que es labor nueva. Lisboa. Antonio Craesbeck de Mello, 1678-1680. (3 vols.).

(96) «La peregrinación del mundo de Cubero»

CUBERO SEBASTIAN, Pedro: Peregrinación del Mundo, del Doctor Don... Nápoles. Carlos Porsile, $1682^{38}$.

Este sacerdote aragonés, misionario apostólico, narra su paso de España a Roma, sus viajes por Europa Oriental, además del que realizó por Asia y Oceanía volviendo a España a través de México.

(22) «El devoto peregrino»

CASTILLO, Fray Antonio del: El devoto peregrino y viage a Tierra Santa. Madrid. Imprenta real, $1654^{39}$.

En conexión con este capítulo de viajes encontramos apropiado situar a aquellas obras que, tratando de la historia reciente de los lugares en los que se centra, no dejan de describirlos al mismo tiempo. Entre ellas tendríamos en primer lugar

${ }^{37}$ PALAU. Op. cit. vol. V. p. 122. Las ediciones más recientes son las de Madrid, 1648 y Alcalá, 1666.

${ }^{38}$ Preferimos esta edición a las demás por coincidir las dos primeras palabras del título con las del documento. PALAU. Op. cit. vol. III. p. 343.

${ }^{39}$ Esta obra alcanzó una gran popularidad, como lo demuestra las numerosas ediciones que de ella se hicieron. La propia Imprenta real la reimprimió en Madrid en 1656, 1664 y 1700 , así como J. Buendía en 1665 . A parte de estas, las ediciones que reseña PALAU, Op. cit. vol. II. p. 95, hasta 1709 son París. Antonio Mureto, 1664 y 1666, Barcelona y Granada.

"CUADERNOS DE ESTUDIOS GALLEGOS", Tomo XLII, Fascículo 107, Santiago 1995. 
(42) «Conquista de Canarias»

NUÑEZ DE LA PEÑA, Juan: Conquista y antiguedad de las islas de la Gran Canaria, y su descripcion. Con muchas advertencias de sus Privilegios, Conquistadores, Pobladores, y otras particularidades en la muy poderosa Isla de Tenerife. Madrid. Imprenta Real, $1676^{40}$.

que estaría acompañada de dos libros dedicados a la historia de la América Española, tratando uno del virreinato de la Nueva España y otro de la conquista de Florida por Hernando de Soto. El Inca Garcilaso, posee méritos más que suficientes para hacerlo figurar entre los clásicos españoles del Siglo de Oro, y de hecho en ambos capítulos podría contabilizarse

(104) «Historia de la Florida del Inca»

EL INCA GARCILASO DE LA VEGA: La Florida del Inca o Historia del adelantado Hernando de Soto, Governador y capitan general del Reyno de la Florida y de otros heroicos cavalleros Españoles e Indios; escrita por... Lisboa. Pedro Crasbeeck, 1605.

Por su parte el poeta y dramaturgo, Antonio de Solís, cronista mayor de las Indias entre 1661 y 1686, no quedó a la zaga en cuanto a la aceptación de su Historia de la Nueva España, texto encomiástico de las virtudes de Cortés.

(47) «La nueba España de Soliz»

SOLIS Y RIVADENEIRA, Antonio de: Historia de la conquista de Mexico, Poblacion, y progressos de la America Septentrional, conocida por el nombre de Nueva España. Escribiola Don... Secretario de Su Magestad, y su Chronista mayor de las Indias. Y la pone a los pies del Rey Nuestro Señor, Conde de Oropesa. Madrid, Bernardo de Villa Diego, Impressor de Su Magestad, $1684^{41}$.

Pasando a la historiografia propiamente dicha, hallamos el magno trabajo del Padre Mariana, aún hoy punto de referencia necesario dentro de este campo,

${ }^{40}$ SIMÓN. Op. cit. p. 663, y PALAU. Op. cit. vol. V. p. 331.

${ }^{41}$ PALAU. Op. cit. vol. XXI. pp. 464-465, menciona ediciones en 1691 y dos en 1704, además de otras posteriores a 1709 .

"CUADERNOS DE ESTUDIOS GALLEGOS", Tomo XLII, Fascículo 107, Santiago 1995. 
(167) «Historia de Mariana, dos tomos»

MARIANA, Juan de: Historia general de España. Compuesta primero en latin, despues buelta en castellano por Juan de Mariana. Toledo. Pedro Rodríguez. $1601^{42}$.

Dos historias de carácter regional la completaban

(159) «Cronica del Reyno de Valencia»

VICIANA, Martín de: Crónica de Valencia. Libro quarto de la cronica de la Inclita ciudad de Valencia, compilada por Martin de Viciana, scriptor de vista en el qual se contienen las discordias, guerras y muertes causadas por la conjuración plebea nombrada germania por los inventores della. Barcelona. Pablo Cortey, $1566^{43}$.

(169) «Abarca. Anales de Aragon»

ABARCA, Pedro: Los Reyes de Aragon en Anales historicos. Distribuidos en dos partes... por el Padre... de la Compañia de Jesus. Madrid. Imprenta Imperial. Año de $1682^{44}$.

Del autor del célebre Teathro eclesiastico, era esta primera de las dos biografias regias que se recuentan

(173) «Gill Gonzales. Historia de Enrique tercero»

GONZALEZ DAVILA, Gil: Historia de la vida y hechos del rey Don Henrique tercero de Castilla, inclito en Religion y Justicia. Madrid. Francisco Martinez, 1630.

siendo la otra

(109) «Sandobal. Historia de Carlos quinto»

SANDOVAL, Prudencio de: Historia de la vida y hechos del emperador Carlos $V$. Valladolid. Sebastian de Canes, 1604-1606. (2 vols. $)^{45}$.

${ }^{42}$ La edición más próxima a la muerte de don Andrés es la de Madrid. León de Francia, 1679.

${ }^{43}$ Aunque encontramos dudosa esta identificación, nos parece más probable que hacerlo con la de Pedro Antonio BEUTER: Segunda parte de la Coronica general de España y especialmente de Aragon, Cathaluña y Valencia. Valencia. Joan de Mey, 1551.

${ }^{44}$ PALAU (Op. cit. vol. I. p. 3) cita como más próxima la impresión de 1684.

${ }^{45}$ La edición más próxima es de Pamplona. Bartolomé París, 1634.

"CUADERNOS DE ESTUDIOS GALLEGOS", Tomo XLII, Fascículo 107, Santiago 1995. 
cuyo lógico complemento dentro de nuestra biblioteca es la obra de Paulo Jovio

(119) «Hestoria general de Paulo Otobio»

JOVIO, Paulo: Historia general de todas las cosas succedidas en el mundo en estos cincuenta años de nuestro tiempo, en la qual se escriven particularmente todas las victorias y successos que el invictisimo Emperador Don Carlos uvo dende que començo a reynar en España hasta que prendio al Duque de Saxonia. Escrita en lengua latina por el doctissimo Paulo Jovio, traduzida de latin en Castellano por el licenciado Gaspar de Baeça. Salamanca. Andrea de Portonariis, 1562.

El tercer gran modelo de caballero, militar y noble es el de Gonzalo Fernández de Córdoba, siendo este ejemplo de vasallo donde los dos primeros eran de reyes

(172) «Historia del Gran Capitan»

JOVIO, Paulo: Libro de la vida y chronica de Gonçalo Hernandez de Cordoba. Llamado por sobrenombre el Gran Capitan. Agora nuevamente traduzida en Romance Castellano por Pedro Blas Torrellas. Amberes. Gerardo Spelmanno. $1555^{46}$.

El agitado mundo político de los siglos XVI y XVII aparece reflejado en las estanterías del palacio Mondragón, en el que se mezclan volúmenes que nos informan tanto de los conflictos internos de Francia o Inglaterra, como de las guerras que desgarraron a la propia monarquía española tanto en la Península como en los territorios ultramarinos de Flandes y América. Habría que considerar en primer lugar un texto peculiar, pues más que una historia política de la monarquía francesa, se trata en realidad de una réplica de la justificación que Besiano Arroyo, canónigo doctoral de la catedral de Lyon, hace del derecho del rey de Francia, como heredero de Carlomagno, a apropiarse de los territorios del antiguo Sacro Imperio

${ }^{46}$ Nos inclinamos por esta y no por la anónima Chronica del gran Capitan Gonçalo Hernandez de Cordoba y Aguilar... Alcalá de Henares. Hernán Ramírez, 1584, por poseer don Andrés otra obra de este autor.

"CUADERNOS DE ESTUdiOS GALlEGOS", Tomo XLIl, Fascículo 107, Santiago 1995. 
Romano Germánico. Moncada ${ }^{47}$, que dice traduzir del latín y del francés a un tal Alexandro Patricio Armacano, teólogo, dedica sus afanes a desmontar esta teoría, pero también a demostrar, en especial a todos los reyes cristianos - como destaca el obispo de Plasencia en su aprobaciónla injusticia de la guerra y «el mar de errores y daños lastimosos que se siguen de las ligas con Hereges y Turcos, y con todos los que favorecen a los rebeldes, a sus Reyes, y prefieren la razon de Estado a la obediencia de la Religion Christiana».

(106) «Marte frances»

MONCADA, Sancho de: Marte frances o de la iusticia de las armas y confederaciones del Rey de Francia. De Alexandro Patricio Armancano, Theologo. Dedicado al Principe Nuestro Señor. Traducido de latin y frances por el Doctor.. Madrid. Imprenta Real. $1637^{48}$.

En su dedicatoria al príncipe Baltasar Carlos, le insta a tomar ejemplo de estas equivocaciones, lo que relacionaría este tratado con aquellos que tanto abundaron durante este siglo destinados a orientar a reyes y futuros soberanos. Nótese también el rechazo del concepto maquiavélico de la razón de estado en que tanto empeño pusieron la mayor parte de los clérigos que sobre ello teorizaron en la España de la época y sobre el que más adelante volveremos.

De las plumas de sendos autores italianos nacieron estas crónicas, que brindaban a sus lectores el conocimiento de las guerras civiles de Francia e Inglaterra.

(142) «Guerras civiles de Caterino»

CATERINO DAVILA, Enrico: Historia de las guerras civiles de Francia. Traduzida del idioma toscano... por el M.R.P. Basilio Varen Soto. Madrid. Sánchez, $1651^{49}$.

${ }^{47}$ Moncada se presenta a si mismo en la portada del libro como Cathedratico de propiedad de Prima de Philosophia y de sagrada escritura y jubilado en ella y substitucion de Theologia en la Universidad de Toledo y Fiscal de la Camera Apostolica, Rector que fue de la Iglesia de Cabanillas de Henares.

${ }^{48}$ Otra posibilidad, aunque menos clara por lo que conocemos de los intereses de don Andrés sería AYORA VALMISOTO, Hernando: El arbitro entre el Marte Frances y las Vincias Gallicas, Responde Por la Verdad, Por la Patria, Por sus Reyes. Pamplona. Carlos Juan, 1646.

${ }^{49}$ PALAU. Op. cit. vol. II. pp. 115-116. La segunda edición es de Madrid. Andrés García de la Iglesia, 1675

"CUADERNOS DE ESTUDIOS GALLEGOS", Tomo XLII, Fascículo 107, Santiago 1995. 
(19) «Guerra de Inglaterra, un tomo»

BISACCIONI, Majolino: Guerras Civiles de Inglaterra, Tragica muerte de su Rey Carlos Escrita en Toscano por el Conde Mayolino Bisaccioni... Traduixola en lengua castellana D. Diego Felipe de Albornoz... Madrid. Diego Díaz de la Carrera, $1659^{50}$.

Una visión del Imperio Otomano remataría la panorámica de las principales potencias europeas del momento.

(133) «Historia octomana»

LARDITO, fray Juan Bautista: Historia del estado presente del imperio otomano, que traducida, y añadida, ofrece a la luz publica, con un compendio de los progressos de la Liga Sagrada contra Turcos. Salamanca. Lucas Pérez, $1690^{51}$.

Mientras que el cardenal Bentivoglio con su Historia de las guerras civiles de Flandes, nos introduce en los conflictos de propio imperio español

(158) «Beyntebollo. Historia»

BENTIVOGLIO, Guido: Guerra de Flandes... traduxola de la lengua Toscana... el Padre Basilio Varen... Madrid. Francisco Martínez, $1643^{52}$.

La situación en la América española estaba presente a través de la curiosa obra del flamenco Exquemeling, pseudónimo tras el cual, según Murguía, se ocultaba el coruñés afincado en Cádiz, Antonio Freire ${ }^{53}$.

(70) «Piratas de la America, un tomo»

EXQUEMELING, Juan: Piratas de la America, y luz a la defensa de las costas de Indias Occidentales. Traducida de la lengua Flamenca por el Doctor de Buena-Maison. Colonia. Lorenzo Struickman, $1681^{54}$.

${ }^{50}$ BUSTAMANTE Y URRUTIA, J.M.: Catálogos de la Biblioteca Universitaria. Santiago. Universidad de Santiago, 1948. vol. s. XVII-1. p. 328. nº 2539.

${ }^{51}$ SIMÓN. Op. cit. p. 689. n² 2729.

${ }^{52}$ La edición más próxima a 1709 es la de Amberes. Jerónimo Verdussen, 1687.

${ }^{53}$ MURGUíA, Manuel: Galicia. Santiago. Edicións Sálvora, 1984. p. 327. Vid. también Gran Enciclopedia Gallega. vol. I4. p. 109. In voz Freire, Antonio.

${ }^{54}$ El título de la segunda edición de esta obra, (Madrid, 1783) da clara idea de su contenido: Piratas de la America y luz a la defensa de las costas de las Indias occidentales, en que se trata de las cosas notables de los viajes, descripción de las islas Española,

"CUADERNOS DE ESTUdios GALlegOS", Tomo XliI, Fascículo 107, Santiago 1995. 
Si los ataques a las líneas de comunicación entre España y las Indias pusieron en serios aprietos a la monarquía, no resultó de menor gravedad el asentamiento holandés, finalmente frustado, en las costas de Bahía y de Recife, y que se prolongó hasta más allá de la secesión de Portugal, de esto trataba

(134) «Guerras del Brasill»

ALBURQUERQUE COELHO, Duarte de:Memorias diarias de la guerra de Brasil, por discurso de nueve años, empeçando desde el de MDCXXX. Madrid. D. Díaz de la Carrera, 1654.

Como comprobaremos a partir de ahora, los literatos portugueses abundan en la nómina de autores que nos es preciso examinar. Francisco Manuel de $\mathrm{Melo}^{55}$, a la par que destacado escritor, es una de esas personalidades, que como la de el renombrado dramaturgo Gil Vicente, cultivaron además de su propio idioma, la lengua castellana. Su publicación más destacada en esta lengua, publicada en 1645, relata los primeros años de la Guerra de Cataluña.

(68) «Historia de Cataluña»

MELO, Francisco Manuel de: Historia de los movimientos, separación y guerra de Cataluña y de la Guerra entre la Magestad catolica de Don Felipe el Cuarto... y la Diputación General de aquel principado. Lisboa. Paulo Craesbeeck, $1645^{56}$.

Si la anterior está considerada como su trabajo más destacado en castellano, también de carácter histórico son sus Exanaphoras, la principal de sus obras en lengua portuguesa.

Tortuga y Jamaica, de sus frutos y producciones, politica de sus habitantes, guerras y encuentros entre españoles y franceses, origen de los piratas y su modo de vivir, la toma $e$ incendio de la ciudad de Panama, invasion de varias plazas de la America por los robadores franceses Lolonois y Margan.

${ }^{55}$ De origen noble, Francisco Manuel de Melo (1608-1666) sirvió a los Austrias como militar en Flandes, Galicia y sobre todo en la campaña de Cataluña, hasta el momento de la Secesión de Portugal en que pasó de nuevo a Lisboa en 1641. Participó en 1639 en la defensa de A Coruña contra un ataque francés y fue gobernador de Baiona durante 1640 .

${ }^{56}$ Existe una $2^{\mathrm{a}}$ edición de Lisboa. Bernardo Costa de Carvalho, 1690. Modernamente fue reeditada por la Real Academia Española en Madrid, en 1912 con el título de Guerra de Cataluña y más recientemente en Barcelona. Ed. Mompel, 1981.

"CUADERnOS DE ESTUdiOS GALLEGOS", Tomo XLII, Fasciculo 107, Santiago 1995. 
(72) «Apanaforas de Juan Manuel»

MELO, Francisco Manuel de: Exanaphoras de varia historia portugueza. Lisboa Craesbeeck de Mello, $1676^{57}$.

En 1651 se publicó la Carta de guia de casados, que pretendía servir de orientación a aquellos matrimonios que hubiesen de vivir en los ambientes cortesanos.

(88) «Carta y guia de casados»

MELO, Francisco Manuel e AUREN DE MELLO, L.: Carta de guia de casados. Para que pello caminho de prudencia se acerte com a casa do descanso. Lisboa. Officina Craesbecckiana, $1651^{58}$.

Salida de su pluma originalmente en castellano también, sus Obras morales, impresas en Roma en 1664, contenía tres partes: La vitoria del hombre, El Fenix de Africa y El mayor pequeño en la edición de Lisboa de 1648 , mientras que en la de Roma, se añadía otras cinco.

(97) «Obras morales de Don Francisco Manuel en tres tomos»

MELO, Francisco Manuel: Obras morales. Roma. Falco y Varezio, 1664.

Don Francisco Manuel osciló entre la literatura moral y la política, como tantos otros autores de su tiempo, empezando por su admirado Quevedo. De hecho, casi ningún género de la literatura barroca escapa por completo a la corriente prudencialista, que buscaba en la literatura un conjunto de fórmulas y técnicas con las que sobrellevar el mundo ${ }^{59}$. Así resulta a menudo difícil dintinguir claramente los límites entre los escritos políticos, históricos, filosóficos y religiosos. De los concebidos para servir de orientación a príncipes y hombres de Estado, encontramos una excelente selección que confirma la vocación política de don Andrés y seguramente también de su padre y sus antecesores. El más antiguo de estos tratados es la

\footnotetext{
${ }^{57}$ Fue publicada por primera vez en Lisboa en 1660 .

${ }^{58}$ La primera edición que hemos localizado en castellano fue publicada en Madrid por Villanueva en 1724 con el título de Carta de guia de casados y avisos para palacio.

${ }^{59}$ RALLO GRAUS, Asunción: La prosa didáctica en el siglo XVII. Madrid. Taurus, 1988. p. 71.
}

"CUADERNOS DE ESTUdiOS GALLEGOS", Tomo XLII, Fascículo 107, Santiago 1995. 
Caída de príncipes de Giovanni Boccaccio ${ }^{60}$.

(48) «Cayda de Principes de Boecio»

BOCCACCIO, Giovanni: Cayda de principes. Alcalá de Henares. Juan de Brocar, 1552.

La edición que citamos es la última que hemos conseguido localizar, lo que nos sitúa claramente en los tiempos del cardenal don Juan de Mondragón, como ocurre con las obras de Paulo Jovio y de Sandobal a que nos hemos referido más arriba. Muy probablemente formaron parte del universo de lecturas de este clérigo - y a caso del licenciado don Juan de Mondragón - las obras del obispo de Mondoñedo y antiguo cortesano de Carlos V, fray Antonio de Guevara.

(15) «Las cartas de Guebara»

GUEVARA, fray Antonio de: Epistolas familiares del illustre don... Valladolid. Juan de Villaquirán, 1539.

Mucho más dentro de lo político, aunque como el mismo dice con la pretensión de ser útil no sólo a los gobernantes, sino a cualquier cristiano, estaría su Marco Aurelio

(83) «Emperadores de Guebara»

GUEVARA, Antonio: Libro del emperador Marco Aurelio con el relox de principes, auctor del qual es el obispo de Guadix. Valladolid. Nicolás Tierry, $1529^{61}$.

La gran mayoría de los autores del siglo XVI y XVII que abordaron la teoría política, especialmente en España e Italia, coincidían en la idea de que el origen de la autoridad provenía en Dios, de manera que el rey estaba sujeto a un compromiso religioso en sus acciones, Boccalini, Botero, Lipsio, el Padre Rivadeneyra formaban parte de una larga tradición que

\footnotetext{
${ }^{60}$ Fue traducido al castellano antes que ningún otro tratado de Boccaccio, puesto que ya en 1422 el obispo de Burgos, Alonso de Catagena lo había dado a la imprenta. No deja de ser curiosa la confusión del redactor del recuento cuando atribuyéndola a Boecio. Tal vez le resultase nombre más familiar.

${ }^{61}$ De este hay una edición de 1658 hecha en Madrid por Melchor Sanz.
}

"CUADERNOS DE ESTUDIOS GALLEGOS", Tomo XLII, Fascículo 107, Santiago 1995. 
se oponía a las ideas del maquiavelismo sobre la razón de Estado, concediendo a este con criterios providencialistas, fines transcendentales. De los dos primeros encontramos recontados

(52) «Trajano Boscalini. Dos tomos de Avissos»

BOCCALINI, Traiano:Discursos Politicos, y Avisos del Parnasso de... Tradujolos de la lengua toscana en la Española Fernando Peres de Sousa. Madrid. María de Quiñones, 1634. (2 vols. $)^{62}$.

(40) «Antonio de Herrera. De Razon de Estado»

BOTERO, Juan: Diez libros de la Razon de Estado, Con tres libros De las causas de la grandeza, y magnificencia de las ciudades de Botero. Traducido de Italiano en Castellano por mandado del Rey nuestro señor, Por Antonio de Herrera su criado. Madrid. Luis Sánchez, $1593^{63}$.

Repercusión española de estas teorías es el Gobernador christiano del agustino madrileño fray Juan Márquez, traducido en su día al francés y al italiano, lo cual nos da idea del grado de participación de los escritores españoles en esta tendencia de la teoría política

(166) «Gobernador cristiano»

MARQUEZ, fray Juan: El gobernador christiano deducido de las vidas de Moises y Josue. Pamplona, 1615.

Con todo, el más eminente de los literatos hispanos que abordaron la temática política fue sin duda don Francisco de Quevedo, quien se sumó en obras como su Política de Dios, Gobierno de Cristo al antimaquiavelismo

(2) «Seis thomos de Quebedo»

QUEVEDO Y VILLEGAS, Francisco de: Parte primera y segunda de las obras de... Madrid, 1687.

\footnotetext{
${ }^{62}$ Boccalini (1556-1613) publicó I Raggnali di Parnasso un año antes de su muerte en Venecia, lugar donde se había refugiado huyendo de sus enemigos políticos romanos, por lo que su traducción castellana es relativamente próxima en el tiempo.

${ }^{63}$ PÉREZ PASTOR, Op. cit. vol. I. p. 404. La traducción de Herrera de las obras de Botero (1540-1617) célebre secretario san Carlos Borromeo, funde en un sólo volúmen la Raggione di Stato con su tratado a cerca del poderío y fuerzas de cada uno de los Estados de Europa, que permite considerarle como uno de los fundadores de la ciencia estadística.
}

"CUADERNOS DE ESTUDIOS GALLEGOS", Tomo XLII, Fascículo 107, Santiago 1995. 
De todas formas, en ciertos sectores fue decayendo la oposición a la ciencia política como técnica independiente del estricto sentido religioso, siendo así que Tácito fue elegido para construir un ensayismo político renovador, asimilándolo a las necesidades políticas de la Contrarreforma ${ }^{64}$ En palabras de José Luis Moralejo, el sentido ejemplificador del gran historiógrafo latino, «su densidad ideológica, su capacidad de análisis psicológico y de síntesis expresiva han hecho de Tácito uno de los grandes forjadores de sententiae de frases lapidarias del mundo occidental $»^{65}$. Esta faceta hizo que su primera utilización estuviese ligada a una forma literaria de gran aceptación en el barroco, los emblemas ${ }^{66}$, ya que su principal pretensión consistía en formular recetas que actuasen como prevención de errores. E1 primer gran comentarista de empresas fue el célebre Andrea Alciato

(114) «Emblemas de Alciato»

ALCIATO, Andrea: Los Emblemas Traducidos en rhimas Españolas (por Bernardino Daza Pinciano) Añadidos de figuras y nuevos Emblemas... Lyon. Mathias Bonhome, 1549.

del cual fue consecuencia española el no menos famoso de Covarrubias

(41) «Emblemas de Cobarrubias»

COVARRUBIAS Y OROZCO, Sebastián: Emblemas Morales, de Don..., Capellan del Rey Nuestro Señor, Maestrescuela y Canonigo de Cuenca. Madrid. Luis Sánchez, 1610.

Muy pocos̉ fueron en España los tacitistas puros, sin embargo, existió un abundante grupo de teóricos que adoptaron posturas intermedias, como Enríquez de Villegas, sin dejar de sostener que un buen político ha de ser un buen católico.

(121) «El principe en la ydea de Enriquez»

ENRIQUEZ DE VILLEGAS, Diego: El Principe en la idea. Madrid. Imprenta Real, 1656.

${ }^{64}$ TIERNO GALVÁN, Enrique: El tacitismo en las doctrinas políticas del Siglo de Oro español. Escritos. Madrid. Tecnos, 1971. p. 50.

${ }^{65}$ TÁCITO: Historias. Edición de José Luis Moralejo Álvarez. Madrid. Akal. 1990. Introducción. p. 18-19.

${ }^{66}$ RALLO. Op. cit. p. 71.

"CUADERnOS DE eStudios GALlEGOS", Tomo XLII, Fascículo 107, Santiago 1995. 
Retomando el mundo de las imágenes aplicadas a la didáctica política, aparece ante nosotros este muy curioso libro de Ferrer de Valdecebro, acompañado de otro de preceptiva para gobernantes

(31) «Gobierno moral, un tomo»

FERRER DE VALDECEBRO, fray Andrés: Govierno general, moral y politico hallado en las fieras y animales sylvestres. Madrid. Díaz de la Carrera, $1658^{67}$.

(37) «Cetro con ojos»

FERRER DE VALDECEBRO, fray Andrés: El cetro con ojos... Dedicado al Rey de España Carlos Segundo. Madrid. Francisco Sanz, 1677.

Estricto contemporáneo de don Andrés, Félix Lucio de Espinosa (16461691), fue como él político y caballero de una orden militar, la de Calatrava. Sirvió a la Corona en Sicilia como secretario de Estado, pero además ejerció el cargo de cronista de Aragón, Castilla y León y las Indias.

(33) «Escarmientos Politicos»

LUCIO DE ESPINOSA Y MALO, Félix: Declamaciones, escarmientos politicos, y morales que escrivio el Doctor... Madrid. Joseph Fernández Buendía, $1674^{68}$.

Apelando a la fuerza de la religión como motor principal en el impulso que la nobleza de España tenía la obligación moral de dar al país en las horas más bajas del reinado de Carlos II, escribió Cortes y Osorio su Constancia de la fe

(140) «Constancia de la fee de Cortes»

CORTES Y OSORIO, Juan: Constancia y aliento de la nobleza española, que escrive y dedica a los gloriosos reynos de Castilla y Leon... Madrid. Román, $1684^{69}$.

${ }^{67}$ PALAU, Op. cit. vol. 5. p. 370. La edición más cercana es la de Barcelona. Tomás Loriente, 1696.

${ }^{68}$ SIMÓN, Op. cit. p. $12 \cdot \mathrm{n}^{0} 32$.

${ }^{69}$ PALAU, Op. cit. vol. 2. p. 315. No se citan más ediciones.

"CUADERNOS DE ESTUdios GALleGOS", Tomo XLII, Fascículo 107, Santiago 1995. 
Si de todos los anteriores se extraían máximas para el buen gobierno, del Galateo se seguían cuales eran los comportamientos que debían evitarse para no ser tachado de rústico y descortés. Era, pués, un tratado de buenas maneras, en el que se daban orientaciones tan pintorescas como la de no cortarse las uñas en público o no contemplar el pañuelo después de sonarse la nariz

(26) «Galateo, un tomo»

GRACIAN DANTISCO, Lucas: Galateo español agora nuevamente impresso y enmendado. Autor.. criado de Su Magestad y de nuevo añadido el destierro de la ignorancia, que es Quaternario de avisos convenientes a este nuestro Galateo. Y la vida de Lazarillo de Tormes, castigado. Zaragoza. Lorenzo de Robles, $1593^{70}$.

Sin duda habrá llamado la atención de quien lea estas líneas la ausencia de dos autores fundamentales en la literatura política española del siglo XVII, que no son otros que Saavedra y Fajardo y Baltasar Gracián ${ }_{\phi}$ pero no ha de olvidarse que el préstamo o intercambio de libros en esta época era tan frecuente como hoy en día o más, en una sociedad que carecía de la abundancia de entretenimientos de la presente ${ }^{71}$.

Para quien, como el marqués de Santa Cruz, era político y leal servidor del rey, tanto como terrateniente acaudalado, el conocimiento de las leyes no podía descuidarse. Entre las obras recontadas se rastrea la impronta de las sucesivas generaciones de clérigos que habían precedido a don Andrés,

${ }^{70}$ PALAU, Op. cit. vol. 3. p. 391. La edición más próxima es la de Barcelona. Imprenta Matevad, 1680. Baltasar Gracián empleó sus consejos como base de un pasaje de El Criticón (Parte I. Crisi XI.) en el que partiendo de una aparente una serie paradójicas refutaciones de las normas de urbanidad, avisa sobre cuál es la verdadera realidad de la corte.

${ }^{71}$ Este vacío no tiene desde luego sencilla explicación en un repertorio tan selecto como el que nos ocupa. Es, sin embargo, difícil de creer que los escritos de ambos resultasen indiferentes a Mondragón y nos parece necesario señalar la circunstancia de que su vecino, el arquitecto Diego de Romay, si poseyó libros de estos teóricos. Su trato debió ser frecuente, ya que este artista había dado las trazas para la fuente del pazo de Rivadulla y compartido con él labores edilicias en el consistorio municipal durante al año en que ocupó el puesto de procurador general de la ciudad. De hecho, en las elecciones para este cargo, el voto de don Andrés fue para Romay. En cuanto a las obras que éste poseía digamos que de las de Gracián eran El Criticón y Arte de Ingenio, siendo las de Saavedra Corona gótica castellana y Empresas políticas.

"CUADERNOS DE ESTUdIOS GALlEGOS", Tomo XLII, Fascículo 107, Santiago 1995. 
especialmente en los libros de derecho canónigo y en general en los ejemplares escritos en latín, puesto que, a juzgar por el conjunto de las obras que publicadas y editadas en vida de don Andrés están presentes en el documento, parece claro que no dominaba esta lengua, en la cual se hallaban redactados siete volúmenes, idéntico número de obras que en castellano. Comenzando por los cánones estaría,

(195) «Repertorio de Bartolome Zepole»

CEPOLLA, Bartolomeo: Varii tractatus D. Bartholomaei Caepollae veronensis. Venecia, $1580^{72}$.

Estas otras que siguen, pertenecen en su autoría al eximio jurisconsulto y obispo Diego de Covarrubias. El objeto de estudio es en el primer caso el comentario de una parte de las Decretales, siéndolo también en el segundo, aunque en este se interrelacionan derecho canónigo, romano y real, como se sigue ya en su título.

(181) «Cobarrubias, Sobre las decretales y (182) barias recolecciones» COVARRUBIAS DE LEIVA, Diego: In librum quartium Decretalium, ex tertia autoris recognitione. Salamanca. Juan Canova, 1556.

- Varie resolutiones ex Iure Pontificio, Regio et Caesareo, 1552.

Continuando con el derecho canónigo hallamos

(151) «Ojeda, De yncomposibilitate beneficiorum»

OJEDA DE MENDOZA, Alfonso: De beneficiorum Incompatibilitate atque Compatibilitate Tractatus. In cuis parte prima de variis incompatibilitatum species agitur. In secunda autem casus omnes, in quibus multa beneficiarii sunt compatibia traduntur. Venecia. Giovanni Varisco, 1579.

así como los comentarios al título LX del libro VI del Código de Justiniano del portugués Arias Pinelo

(143) «Arias Pinelo, Sobre el codijo»

PINELO, Arias: Ad Constitutiones Codicis de bonis maternis, et ad

${ }^{72}$ Bartolomeo Cepolla, canonista italiano muerto en 1477, enseñó en Padua y Verona.

"CUADERnOS DE ESTUdIOS GALlEGOS", Tomo XLII, Fascículo 107, Santiago 1995. 
Rubricas Codicis de resudenda venditione commentarii. Salamanca. Matias Gastius, 1573.

(148) «Practica singular de Salcedo»

DÍAZ DE LUGO, Juan Bernal: Practica criminalis canonica.Lyon.

Sin impresor, 1549, (obra comentada por Ignacio López Salcedo).

Si antes teníamos ante nosotros a Diego de Covarrubias, aparece ahora otro de los representantes de la brillante escuela iusnaturalista castellana del siglo XVI, abordando un tema central para la monarquía y la sociedad de la época, como era el de los mayorazgos ${ }^{73}$

(161) «Molina, De primo geneis»

MOLINA, Luis de:De Hispanorum Primogeniorum origine ac natura.

Libri quatuor. Alcalá de Henares.' A. de Angulo, 1573.

Pasando ya al derecho castellano, el código de más antigua redacción de los que aquí se hallaban son las Leyes de Estilo, que basadas en el Fuero Real, recopilaba las interpretaciones legales de la corte castellana desde Alfonso X hasta Fernando IV, cuya importancia radicaba en el Derecho penal y procesal ${ }^{74}$.

(179) «Fuero real y leyes del estilo»

Leyes del estilo y declaraciones sobre las leyes del fuero. Salamanca, $1497^{75}$.

Tampoco está ausente el primer gran código recopilativo castellano, las Leyes de Toro, a través de una glosa que lo estudia.

(138) «Cifuentes, Sobre las leyes de Toro»

CIFUENTES, Miguel de: Glosa de Miguel de Cifuentes sobre las leyes de Toro. Quaderno de las leyes y nuevas decisiones, hechas y ordenadas en la ciudad de Toro, sobre las dudas de derecho que continua-

${ }^{73}$ GIBERT, Rafael: Ciencia jurídica española. Granada. Imprenta de Francisco Román, 1982. p. 16.

${ }^{74}$ LALINDE ABADÍA, Jesús: Iniciación histórica al derecho español. Barcelona. Ariel, 1978.

${ }^{75}$ PALAU, Op. cit. vol. IV, p. 231, cita como edición más próxima la de Salamanca, Juan Bautista de Terranova, 1569.

"CUADERNOS DE ESTUDIOS GALLEGOS", Tomo XLII, Fascículo 107, Santiago 1995. 
mente solian y suelen ocurrir en estos reynos... Medina del Campo, Pedro de Castro, $1546^{76}$.

De todas las identificaciones de este apartado jurídico las menos claras son las siguientes

(178) «De lege del reyno»

(139) «Repertorio general de las leyes»

Repertorio de las leyes de todos los reinos de Castilla. Valladolid. Juan de Villaquirán, 1547.

(177) «Nueba recopilacion»

ATIENZA, Bartolomé: Repertorio de la nueva recopilación de las leyes del Rey. Alcalá de Henares. A. de Angulo, 1567.

El título de la primera se nos antója casi imposible de localizar, tanto por su absurda transcripción como por la falta de datos ${ }^{77}$. En cuanto al tercero, parece evidente que se trata de la comunmente conocida como Nueva recopilación, que fue tan criticada como utilizada, y cuya elaboración, en opinión de Lalinde Abadía, sólo se justifica por la incorporación de las Leyes de Toro $^{78}$. Complementario del anterior, publicó en Salamanca Núñez de Avendaño este volumen conteniendo cuatro tratados acompañados de un glosario, en el que se comentaban las leyes reales.

(146) «Libro yntitulado Quadraginta responsa»

NUÑEZ DE AVENDAÑO, Pedro: Quadraginta responsa, quibus quamplurimae leges regiae explicantur, etc. Salamanca. Juan Canova, 1569.

De la pluma del canónigo, catedrático y varias veces rector de la Universidad de Granada, Bermúdez de la Pedraza, procede esta descripción minuciosa de las instituciones de la administración, que toma como punto de partida el Digesto ${ }^{79}$

\footnotetext{
${ }^{76}$ También fue editada en la misma ciudad por Francisco del Canto en 1556.

${ }^{77}$ Algunos de los títulos posibles que hemos barajado son las obras de Sepúlveda, De regno et regis officio, Fox Morcillo, De regis instituione y del Padre Mariana, De rege et regis institutione.

${ }^{78}$ LALINDE ABADÍA, Op. cit. p. 196.

${ }^{79}$ Sobre Bermúdez de la Pedraza, véase SEMPERE, Juan: Historia del derecho español: Madrid. Imprenta de González y Vicente, 1847. Cap. IX. Idea de un jurisconsulto español del siglo XVII. pp. 489-492.
}

"CUADERNOS DE ESTUDIOS GALLEGOS", Tomo XLII, Fascículo 107, Santiago 1995. 
(186) «Bermudes, Arte legal»

BERMUDEZ DE LA PEDRAZA, Francisco: Arte Legal para estudiar la Jurisprudencia con la exposición de las Instituciones de Justiniano. Madrid. Francisco Martínez, 1633.

La profundización en uno de los aspectos de la estructura jerárquica del Estado, fue el objetivo de Núñez de Avendaño, en su comentario de la legislación sobre los corregidores

(135) «Muños, De exequentis mandatio regum» NUÑEZ DE AVENDAÑO, Pedro: De Exequentis Mandatis Regum Hispaniae, quae Retoribus Civitatum dantur, et hodie continentur in titulo 6 liber 3. Recopilationes vulgo nuncupatis Capitulos de Corregidores, etc. Alcalá de Henares, $1543^{80}$.

Una de las más difundidas y reeditadas monografias legales del siglo XVII, fue la Curia filipica, en la que, aunque como se ve por el título se explican sobre todo asuntos concernientes al derecho mercantil, también se extiende sobre aspectos del derecho procesal ${ }^{81}$

(180) «Curia filipica»

HEVIA BOLAÑOS, Juan de: Curis Filipica. Primera y segunda parte. Donde breve y compendiosamente se trata de los juyzios, mayormente forenses, ecclesiasticos y seculares, con lo sobre ello hasta ahora dispuesto por Derecho, resuelto por Doctores, antiguos y modernos y practicable... Segunda Parte. Donde breve y compendiosamente se trata de la Mercancia y Contratacion de Tierra y Mar... Madrid, $1684^{82}$.

Reseña especial merece el Fuero de Vizcaya, puesto que, si por un lado no debería causar sorpresa dado el origen vasco de los Mondragón, la base teórica que haya proporcionado en manos de un diputado de la Junta del

${ }^{80}$ Según PALAU, Op. cit. vol. V. p. 329, esta primera edición se encuentra hoy perdida. Posteriormente se reeditó en Salamanca por Juan Canova, 1564 y Alejandro Canova, 1573 y en Madrid por Pedro Madrigal en 1593. La última edición se hizo en Nápoles por T. Longhi en 1620 .

${ }^{81}$ Sobre Juan de Hevia, véase GIBERT, J. Op. cit. p. 17.

${ }^{82}$ La primera edición es de Ciudad Real, Antonio Ricardo, 1603 y la más próxima a 1709 la de Madrid, Jerónimo Estrada de 1700.

"CUADERNOS DE ESTUDIOS GALLEGOS", Tomo XLII, Fascículo 107, Santiago 1995. 
Reino de Galicia a las aspiraciones políticas de este órgano es asunto que tal vez mereciese ser estudiado.

(136) «El fuero de Biscaia»

El Fuero, Privilegios, Franquezas y Libertades de los Cavalleros hijosdalgo del Señorio de Vizcaya. Bilbao. Pedro Huydobro, $1643^{83}$.

Antes de despedirnos del ámbito jurídico, hemos de confesar que no hemos sido capaces de localizar el tomo recontado bajo el epígrafe

(13) «Valdecebo. De anima leys, un tomo»

y que por estar escrito en latín tal vez se trate de un tratado del siglo XVI, del mismo modo que el apellido del autor a caso sea Valdecebro, por ser este más común.

Unas líneas más arriba indicábamos las dificultades para separar nítidamente los tratados sobre aspectos puramente morales de los que se ocupaban de las tareas políticas. Después de todo, no dejaban de ser diferentes facetas de una misma idea: el regir la propia vida encaminándola hacia una perfección cuyo último objetivo estaba en la consecución de la salvación eterna. Así pues, no debe extrañar el hecho de que el transfondo de buena parte de la biblioteca del I marqués de Rivadulla estuviese impregnada de esta aspiración que desde hacía más de doscientos años parecía embargar a toda la sociedad peninsular, convirtiendo a la santidad en el modelo social seguido por gentes de todas las categorías. En una, a nuestro entender, afortunada comparación, S.G. Payne ${ }^{84}$ establece un paralelismo entre la intensidad existente entre la búsqueda de la santidad, y el afán con el que hoy se procura el éxito económico, las hazañas atléticas o la fama escénica. Pues bien, de los ciento noventa y seis títulos recontados, sesenta y nueve trataban de asuntos religiosos, a los que se podrían añadir cuatro más por versar sobre filosofía moral y tomística. Superaban por lo tanto un tercio del total. Comenzando por estos mismos, hay que reseñar las obras de dos extranjeros: Tesauro y Antoine Goudin. El turinés Enmanuele Tesauro (15911677) fue ante todo un historiador especializado en trabajos sobre su patria, el Piamonte, y su ciudad natal, escritos algunos de ellos por encargo del duque de Saboya.

\footnotetext{
${ }^{83}$ PALAU, Op. cit. p. 284. La más próxima es la de Bilbao, Antonio de Zafra, 1704.

${ }^{84}$ Para una síntesis sobre este asunto, vid. PAYNE, Stanley G.: La España imperial. Madrid. Globus Comunicación, 1994. p. 69-70.
} 
(64) «Filosofia moral de Tesauro»

TESAURO, Manuel: Filosofia Moral derivada de la alta fuente del grande Arisoteles Stagirita. Escribiola en toscano el Conde... Turinense, traducela... Gomez de la Rocha y Figueroa. Lisboa. Antonio Craesbeck de Mello, $1682^{85}$.

Al dominico francés Goudin (1639-1695) pertenece

(90) «Filosofia de Goudin en quatro tomillos»

GOUDIN, fray Antonio: Philosophia tomistica. Madrid, $1788.4 \mathrm{vols}^{86}$.

mientras que por afinidad citaremos ahora la Summa de Enrique Villalobos, profusamente reeditada durante el siglo XVII

(144) «Billalobos. Summa en dos tomos»

VILLALOBOS, Enrique: Summa de Theologia moral y canoniga...

Salamanca. Diego de Cossio, $1622^{87}$.

y el del capuchino Corella (1657-1699), teólogo y predicador de la corte de Carlos II.

(44) «Corrella, tres tomos»

CORELLA, Jaime: Summa de la teologia moral o sean conferencias morales. Madrid, 1695. 3 vols.

Entrando de lleno en el análisis de los libros religiosos es obligado empezar por un ejemplar de la Biblia

(108) «Biblia Sacra»

BIBLIA SACRA, cum duplici translatione, et Scholiis Francis Vatabli, nunc denuo a plurimis erroribus repurgatis, doctissimorum

${ }^{85}$ PALAU. vol. XXIII. p. 107. La segunda edición se hizo en Madrid por Juan García Infanzón en 1692.

${ }^{86}$ PALAU. Op. cit. vol. III. p. 386. Esta es la única edición que hemos localizado. Tal vez la que poseyese don Andrés fuese impresa en Francia en latín.

${ }^{87}$ PALAU. Op. cit. vol. XXVII. pp. 124-126. Se hicieron de él 10 ediciones, siendo la última la de Madrid, 1682, impresa precisamente en dos volúmenes.

"CUADERNOS DE ESTUdIOS GALLEGOS", Tomo XLII, Fascículo 107, Santiago 1995. 
Theologorum, tam almae Universitatis Salmanticensis quam Complutensis iudicio. Salamanca. Gaspar de Portonaro y Guillermo de Rovillo, 1584. (2 vols.)

Los escritos de los grandes doctores de la Iglesia, apenas hacen acto de presencia. Solamente hallamos una obra de san Gregorio, pero reseñada de modo tan inconcreto, que ni siquiera alcanzamos a discernir si se trata de san Gregorio Magno, san Gregorio papa o san Gregorio Nacianceno

(190) «San Gregorio, un tomo»

Doctora de la Iglesia también y por excelencia es santa Teresa de Jesús, doblemente representada aquí

(17) «Dos tomos de cartas de Santa Theresa (18) y dos de Avissos» JESUS, Teresa de: Cartas con notas de Juan de Palafox. Bruselas. Foppens, $1674^{88}$.

- Avisos espirituales comentados por el Padre Alonso de Andrade de la Compañia de Jesus. $1^{\mathrm{a}}$ parte Madrid, 1647. $2^{\mathrm{a}}$ parte Barcelona, $1695^{89}$.

La célebre consejera del rey Felipe IV, la madre Agreda, influyó no poco en la vida espiritual y política del monarca, formando ella misma parte de la corriente mística que floreció en España durante los siglos XVI y XVII ${ }^{90}$.

(73) «Madre Agueda, tres tomos»

AGREDA, Sor María Jesús de: Mistica ciudad de Dios. Madrid. B. de Villa Diego, 1670. (3 vols.) $)^{91}$.

\footnotetext{
${ }^{88}$ Aunque existe una edición de Madrid. María de Quiñones, 1662, esta que escogemos estaba en dos volúmenes como la del recuento.

${ }^{89}$ Ambas partes fueron publicadas en Barcelona por Tomás Loriente en 1695 y 1700 respectivamente.

${ }^{90}$ Sobre esta relación véase STRADLING: Felipe IV y el gobierno de España. Madrid, 1989. Felipe y Sor María. pp. 381-391.

${ }^{91}$ PALAU. Op. cit. vol. I. p. 18. Del mismo año hay una edición de Lisboa, Antonio Craesbeeck de Mello en tres volúmenes.
}

"CUADERNOS DE ESTUDIOS GALLEGOS", Tomo XLII, Fascículo 107, Santiago 1995 
Destaca dentro de este movimiento el dominico fray Luis de Granada (15041588), que como es sabido vivió a caballo entre España y Portugal, siendo su figura particularmente apropiada para servir de enlace con el siguiente grupo de escritores, notables predicadores como él todos ellos, y portugueses algunos.

(3) «Tres thomos de fray Luis de Granada»

GRANADA, fray Luis de: Obras con la vida del autor por el Padre Juan de Arrieta. Madrid. Juan García Infanzón, 1676 y 1679. 3 vols.

(7) «fray Phelipe Dias, un tomo»

DIAZ, fray Felipe: Summa praedicantur. Salamanca, 1589. (2 vols $)^{92}$.

El pensamiento religioso se expresó a menudo por vía de los sermones, forma literaria de gran difusión, que por estar en principio destinada a su elocución pública, logró atraer en torno a los grandes oradores sacros a verdaderas multitudes entre las que se contaban reyes y los cortesanos, que los preferían incluso a las comedias, como nos explica J. Luzio de Azevedo en su biografía del Padre Vieira ${ }^{93}$.

(111) «Vieira: Sermones del rosario, dos tomos»

VIEIRA, Antonio de: Maria Rosa Mystica, excelencias poder y maravillas de su rosario, compendiada en treinta sermones, asceticos, panegiricos, sobre los dos Evangelios de esta Solemnidad, Nuevo y antiguo. Por el Padre... Primera parte traducida del portugues en Castellano por el Reverendisimo P. M. Fr. Lucas Sanz... Madrid. Lorenzo García, 1688.

$2^{\mathrm{a}}$ parte. Traduzida de portugues en castellano por el P. F. Manuel Olivaes. Madrid. Juan García Infanzón, $1689^{94}$.

(99) «Bieyra: Sermones, quatro tomos»

VIEIRA, Antonio de: Sermones varios del padre... Madrid. Juan García Infanzón, $1680^{95}$.

${ }^{92}$ PALAU. Op. cit. vol. 3. p. 46. No es segura la correspondencia con esta obra, por que fue editada como se ve en dos tomos. Del mismo en seis volúmenes es Quadriplicum cancionum. Salamanca, 1583.

${ }^{93}$ LUCIO DE AZEVEDO, J.: História de António de Vieira. Lisboa. Classica Editora, 1992. vol. I. p. 54.

${ }^{94}$ PALAU. vol. XXVI. pp. 465-477.

${ }^{95}$ Dividida en siete partes, con estos cuatro tomos se llegaría hasta la cuarta.

"CUADERNOS DE ESTUDIOS GALLEGOS", Tomo XLII, Fascículo 107, Santiago 1995. 
En cierto sentido, el papel que desempeñaban los predicadores es comparable con el de los articulistas de fondo de nuestros periódicos. Los temas abordados por Vieira tomaban como punto de partida asuntos de carácter moral, pero su desarrollo los relacionaba a menudo con circunstancias de viva actualidad. Así en uno de los Sermones del Rosario se relata la fallida expedición de la flota hispano-portuguesa en el intento de recuperar la ciudad brasileña de Pernambuco ${ }^{96}$, mientras que en otros se aborda el proyecto de boda entre la infanta María Teresa de España y el príncipe heredero de Portugal, don Teodosio ${ }^{97}$, o la importancia de tener enemigos, dado que sólo los hombres sin talento no son envidiados ${ }^{98}$. Así pués, nada más alejado de complejas disquisiciones teológicas sobre abstractos temas espirituales, que los escritos de este jesuita portugués. No acaba aquí la presencia de los clérigos lusos, por el contrario, son tres autores más los presentes, comenzando por otros tres predicadores.

(98) «Sermones de Almeyda en tres tomos»

ALMEIDA, Christovam de: Sermões varios que pregou o... D. Fr. Christovam de Almeida, Da Ordem dos Eremitas de S. Agostinho. Lisboa. Miguel Deslandes, 1680 .

(43) «Bluthean: Primicias evangelicas»

BLUTEAU, Rafael:Primicias Evangelicas do Padre D. Rafael Bluteau, clerigo regular theatina da divina Providencia, calificador do Santo Officio... Lisboa. Joam da Costa, 1676.

(67) «Olveyra: Sermones barios, un tomo»

OLIVEIRA, fray Joseph: Sermões varios. Coimbra, 1688.

y continuando por Mateo Ribeiro, que lo estaba por partida triple

(71) «Alibio de tristes, un tomo»

RIBEIRO, Mateo: Alivio de tristes y consuelo de quexosos, expresado en varias historias, confirmado con exemplares, adornado con autoridades de Santos Padres y sentencias de philosophos antiguos. Traducido del portugues por el Doctor Don Juan Antonio Mora. Barcelona. José Llopis, $1699^{99}$.

${ }^{96}$ LUCIO DE AZEVEDO, Op. cit. pp. 40-41

${ }^{97}$ Idem. pp. 143-144.

${ }^{98}$ Idem. p. 134.

${ }^{99}$ GRAESSE, Jean George Théodore: Trésor de livres rares et précieux. Milán. G.G. Gorlich, 1950. vol. 6. p. 107. La edición portuguesa estaba en tres tomos. Fue publicada en Lisboa por Miguel Deslandes en 1681.

"CUADERNOS DE ESTUDIOS GALLEGOS", Tomo XLII, Fascículo 107, Santiago 1995. 
(92) «Retiro de ciudados de Ribeyro en dos tomos»

- Retiro de ciudados, vida de Carlos e Rosaura. Lisboa, 1681-89100.

(89) «Fortuna Rodada de Ribeyro en dos tomos»

- Roda da fortuna, vida de Alexandre e Jacinta. Lisboa, $1692^{101}$.

Como se ve, las obras del lisboeta Matteos Ribeiro, que fue párroco de Nossa Senhora do Livramento en la segunda mitad del siglo XVII, pertenecen más al género de la novela moralizante que entre la literatura sagrada propiamente dicha, confirmando lo dificultoso de clasificar nuestra biblioteca en géneros estrictamente separados.

Predicador de altura fue el jesuita italiano Paolo Segneri (1624-1694), a quien el papa Inocencio XII nombró teólogo de palacio y que se constituyó en recuperador de la oratoria clásica, siguiendo en sus sermones el modelo ciceroniano, suprimiendo ornamentación y ordenando sólidamente sus argumentos. Su presencia nos pone en relación con la teología vaticana de la segunda mitad del siglo XVII.

(1) «Obras del Padre Señeri en diez y ocho thomos»

SEGNERI, Paolo: El cristiano instruido en su ley. Discursos morales $y$ doctrinales traducidos del toscano por Juan de Espinola Baeza

Echaburu. Barcelona. Jaime Giralt, 1693.

Con mucha diferencia sobre los demás, las biografías de santos y las historias de las órdenes religiosas conforman el grupo más numeroso de cuantos se integran en el presente apartado, enumerándose veintiocho obras, de las cuales, la primera de ellas es el famoso Flos santorum, perfecto comienzo para una lista que se prolonga dilatadamente

(10) «Villegas: Flos santorum, un tomo»

VILLEGAS, Antonio: Flos santorum. Segunda parte y Historia general en que se escrive la vida de la Virgen Sacratisima madre de Dios y señora nuestra y las de los sanctos antiguos. Toledo. Juan Rodríguez, 1586.

${ }^{100}$ GRAESSE, Op. cit. vol. 6. p. 107. No sabemos que haya edición española.

101 Tampoco en este caso conocemos versión castellana que debió de, como se deduce de la gran diferencia que existe en la redacción del título portugués y el que se anota en la documentación.

"CUADERNOS DE ESTUDIOS GALLEGOS", Tomo XLII, Fascículo 107, Santiago 1995. 
(49) «Vida de Soror Francisca Dorotea»

ARANDA, Gabriel de: Vida de Soror Francisca Dorothea. Sevilla.

T. López de Haro, 1685.

(80) «Vida de San Ramon»

COLOMBO, Fray Felipe: Vida del Glorioso Cardenal San Ramon Nonat. Valencia. Antonio González de Reyes, 1676.

(84) «Vida de San Phelipe Neri»

BACHI ARETINO, Jaime: Vida de San Felipe Neri Florentin. Valencia Nogués, $1651^{102}$.

(16) «Vida de Camilo de Leli»

CHICATELI, Sancio: Vida y virtudes del Padre Camilo de Lelis, Fundador de la Religion de los... Ministros de los Enfermos. Madrid. Melchor Sánchez, $1653^{103}$.

Las órdenes religiosas generaron entorno a sí y a sus miembros más destacados un volumen de escritos considerable. Agustinos, capuchinos, franciscanos, dominicos, mercedarios y jesuitas son los que mayor representación alcanzan, todos los cuales, exceptuando el caso de los capuchinos, tenían casa en Santiago.

(155) «Historia de los descalzos (sic) tres tomos»

SAN NICOLAS, fray Andrés de: Historia General de los Religiosos descalzos del Orden de los Ermitaños del Gran Padre, y Doctor de la Iglesia San Agustin, de la Congregación de España y de las Indias. Tomo primero. Desde el año de MDLXXXVIII hasta el de MDCXX dividido en tres decadas. Madrid. Andrés García de la Iglesia, 1664.

JESUS, fray Luis de: Tomo segundo. 1621-1650. Madrid. Luis Antonio de Bedmar, 1681.

SANTA TERESA, fray Diego de: Tomo tercero. 1651-1660. Coordinado y añadido por fray Pedro de San Francisco de Asís. Barcelona. Herederos de J. Pablo y María Martí, $1743^{104}$.

\footnotetext{
${ }^{102}$ Escogemos esta por ser la más parecida en su título al asiento del inventario, pero también podría tratarse del libro de similar encabezamiento de fray Luis Bertrán Marco (SIMÓN. Op. cit. p. 179. $\mathrm{n}^{\circ}$ 805).

${ }^{103}$ BUSTAMANTE, Op. cit. XVII-1. p. 300. nº 2319.

${ }^{104}$ No hemos logrado localizar la edición contemporánea a don Andrés.
}

"CUADERNOS DE eSTUdios GAllegoS", Tomo XLII, Fascículo 107, Santiago 1995. 
Como puede comprobarse, el género hagiográfico fue cultivado tanto por destacados autores laicos, como, mucho más frecuentemente, por cualificados profesos de las correspondientes órdenes e incluso por quienes prefirieron ocultar sus hombres.

(79) «Vida de Santo Thomas de Villanueba»

QUEVEDO, Francisco de: Epitome a la historia de la vida ejemplar y gloriosa muerte del bienaventurado fray Thomas de Villanueva, religioso de la Orden de San Agustin y Arçobispo de Valencia. Madrid. Viuda de Cosme Delgado, 1620.

(86) «Vida de Ysavel de Jesus»

Vida de la Venerable Madre Isabel de Jesus, recoleta agustina en el Convento de San Juan Bautista de la villa de Arenas, Dictada por ella misma. Madrid. S. imp., 1672.

(6) «Parra, Vida de Santa Rosa»

PARRA, fray Jacinto de la: Rosa laureada entre los Santos, epitalamios sacros de la Corte, aclamaciones de España, aplausos de Roma... al feliz desposorio que se celebro en la gloria con Christo de la Beata Virgen Rosa de Santa Maria de la tercera orden de predicadores, patrona del Peru. Madrid. Melchor Sánchez, 1668.

(75) «Vida de San Vicente Ferrer»

GAVALDA, fray Francisco: Vida del angel profeta y apostol valenciano San Vicente Ferrer. Valencia. Jerónimo Vilagrada, 1668.

El valenciano Francisco Gavaldá, por ejemplo, ostentó la mayoría de los cargos eminentes que podía ejercer un dominico, sin excluir los de calificador, consultor y juez ordinario de la Inquisición. Algunos de estos venerables varones y mujeres, muertos en olor de santidad se nos antojan hoy desconocidos, a pesar de haber merecido en su época atención bastante como para que sus vidas fueran recogidas en más de un libro o haber sido ellos mismos escritores.

(81) «Vida de Mariana de Escobar»

MUNIESA, Tomás: Vida exemplar de la Venerable Marina de Escobar. Zaragoza. Pascual Bueno, 1691.

(163) «Doña Mariana de Escobar, dos tomos»

PUENTE, Luis de la: Vida de la venerable Virgen Doña Maria de Escobar, natural de Valladolid, sacada de la que ella misma escribio y segunda parte de la misma vida escrita por el Padre Andres Pinto

"CUADERNOS DE ESTUDIOS GALLEGOS", Tomo XLI1, Fascículo 107, Santiago 1995. 
Ramirez. Madrid. Francisco Nieto, 1665. $1^{\mathrm{a}}$ parte.

- Madrid. Viuda de Francisco Nieto, 1673. $2^{\mathrm{a}}$ parte.

(82) «Vida del Padre Luys de la Puente»

CACHUPIN, Francisco: Vida y virtudes del venerable Padre Luis de la Puente. Salamanca. Diego de Cossio, 1652.

(85) «Vida de fray Manuel de la Fuente»

OXEA, Pedro de: Vida del venerable Padre fray Miguel de la Fuente, gran lustre de la Sagrada Religion de Nuestra Señora del Carmen de la Observancia, clarissimo Espejo de todas las virtudes, varon insigne en fervorosa oracion y altissima contemplacion, portentosa penitencia y aspereza de vida. Zaragoza. Juan de Ybar, 1674.

Otros en cambio se nos hacen familiares, en no pequeña medida por haber sido representados por maestros de la pintura como Zurbarán.

(76) «Vida de San Pedro Nolasco»

COBO Y ORTEGA, Juan: Vida del glorioso San Pedro Nolasco, patriarca y fundador... del orden de Nuestra Señora de la Merced. Cádiz, 1665.

(78) «Vida de San Pedro Paschoal»

PRESENTACION, fray Juan de la: El Machabeo evangelico. Vida del glorioso doctor San Pedro Paschoal de Valencia, Religioso del sacro, real y militar orden de Nuestra Señora de la Merced, redempcion de cautivos, canciller mayor de Castilla, governador del arçobispado de Toledo, obispo de Granada, Jaen y Baeza y martir. Con un apendice de los religiosos de la Merced, que murieron a manos de moros en Granada y otras partes de España. Y vida del santo D. fray Gonzalo Mercador, obispo de Granada. Marid. Imprenta Real, 1671.

El último de los libros dedicados a la orden mercedaria fue escrito por uno de sus miembros, fray Felipe Colombo (1623-1684), hombre que desde el convento de Guadalajara dedicó toda su vida a los libros como censor y cronista general de su religión, siendo notable investigador de archivos y documentos.

(77) «Vida de fray Gonzalo de Amarante»

COLOMBO, fray Felipe: Vida del siervo de Dios V. P. fray Gonzalo

Diez de Amarante, hijo del convento de Lima, del Orden de la Merced. Valencia. Antonio González de Reyes, 1678.

"CUADER NOS DE ESTUDIOS GALLEGOS", Tomo XLII, Fascículo 107, Santiago 1995. 
Si las tres biografías anteriores pertenecen a tres varones ilustres, tres son las santas mujeres a las que honraban los escritos que siguen

(130) «Vida de Doña Ana Ponce de Leon»

ROA, Martin de: Vida de Doña Ana Ponce de Leon, condesa de Feria y despues monja en el monasterio de Santa Clara de Montilla. Córdoba. A. de la Barrera, 1604.

(24) «Vida de la Reyna de Francia»

MANERO, fray Pedro: Vida de la Serenissima Señora Doña Juana de Valois, Reina Christianisima de Francia, fundadora de la Religion de la Anunciata de la Virgen Nuestra Señora, sugeta a la obediencia de la Orden de san Francisco de la regular observancia. Madrid. Imprenta Real, 1654.

Acaso el tema de este otro fuese el mismo

(94) «La mejor liz de Francia»

La mejor lis de Francia. León, $1655^{105}$.

De humilde cuna o de estirpe real, el ejemplo de sus vidas marcó el rumbo de las de miles de dueñas y doncellas de la España del Siglo de Oro.

(87) «Vida de Mariana de Jesus»

MESA, Luis de: Vida, favores y mercedes que Nuestro Señor hizo a la venerable hermana Mariana de Jesus, de la Tercera Orden de San Francisco, natural de la villa de Escalona, que vivio y murio en Toledo. Toledo. Francisco Calvo, 1661.

(129) «Vida de Doña Sancha Alfonsa»

TAPIA Y SALCEDO, Gregorio: Epitome de la vida y milagros de la Serenisima Infanta Doña Sancha Alfonso, hija del Señor Rei Don Alfonso el nono de Leon i Galicia, hermana del Señor Rei Don Fernando de Castilla el Santo, Esposa de Gesu Cristo en el convento de Santa Eufemia de Coçollos de la Orden de Santiago, trasladado al de Santa Fe la Real de Imperial ciudad de Toledo. Madrid. Josef Fernández de Buendía, 1668.

\footnotetext{
${ }^{105}$ PALAU. Op. cit. p. 125, no indica nada más a cerca de este libro que parece haber sido sacado de un catálogo. El título nos hace intuir que su contenido es similar al citado como precedente.
}

"CUADERNOS DE ESTUDIOS GALLEGOS", Tomo XLII, Fascículo 107, Santiago 1995. 
(174) «Vida de soror Gabriela de San Joseph» ${ }^{106}$.

Este ansia de santidad acompañó a los españoles allá a donde llegaron en sus conquistas ultramarinas,

(124) «Vida de San Francisco Solano»

CORDOBA Y SALINAS, Diego: La vida y milagros del Apostol del Peru... fray Francisco Solano. Madrid. Imprenta Real, $1676^{107}$.

Las peripecias vitales de los frailes menores de san Francisco, fueron tratadas tanto en conjunto

(154) «Cronica de los capuchinos»

LISBOA, fray Marcos de: Primera parte de los Chronicas de la Orden de los Frayles menores. Traducion de Diego Navarro. Alcalá de Henares. A. de Salcedo, 1559.

- Parte segunda de las Chronicas de los frayles menores. Alcalá de Henares. A. de Angulo, 1566.

como individualmente,

(56) «El capuchino escoces»

RINUCHINI, Juan Bautista: El Capuchino escoces. Traduzido del italiano por un religioso y lo saca a la luz Don Antonio Velazquez. Madrid. Gregorio Rodríguez, $1647^{108}$.

${ }^{106}$ En ninguna de las obras consultadas hemos hallado referencias de esta biografía.

${ }^{107}$ El franciscano Diego de Córdoba residió en Perú algunos años, antes de regresar a España, donde escribió la vida de este santo. Su obra se editó por primera vez en Lima en 1630, y después en Madrid por la Imprenta Real en 1643, siendo la última la que hemos citado como más probable. Más parecida en cuanto al título, aunque por su remota impresión, debió de gozar de menos probabilidades de llegar hasta Santiago fue esta de CHACÓN, P.: Vida de san Francisco Solano. Puebla de los Angeles, 1658. Tampoco podemos descartar esta otra: ORE, fray Luis Jerónimo de: Relacion de la vida y milagros del venerable padre Fray Francisco Solano de la Provincia de Granada. Murio en la ciudad de Lima, Provincia de los doze Apostoles en 14 de julio de 1610. Madrid. s. imp., 1614.

${ }^{108}$ PALAU. Op. cit. vol. VI. p. 283. La segunda edición es de Madrid. Diego Díaz de la Carrera, 1661. Su protagonista es George Leslie, llamado el arcángel de Escocia.

"CUADERNOS DE ESTUdios GALLEGOS", Tomo XLII, Fascículo 107, Santiago 1995. 
La lista de obras del misionero riojano Mateo de Anguiano es casi tan dilatada como el título de la que consagró a ensalzar la vida de fray Francisco de Pamplona

(95) «El capuchino español»

ANGUIANO, fray Mateo: Vida y virtudes del Capuchino español, el venerable siervo de Dios fray Francisco de Pamplona, Religioso Lego de la Sagrada Orden de Menores capuchinos. Llamado en el siglo D. Tiburcio de Rendin, cavallero de la Orden de Santiago, Señor de la Illustrisima Casa de Rendin y Baron de Viguezas en el Reyno de Navarra. Madrid. Lorenzo Gracia, 1685.

Por su parte al palentino Luis de Guzmán (1544-1605), rector de diversos colegios de la Compañía de Jesús, en Andalucía y Toledo, se le tiene aún hoy en día por autoridad principal en el asunto de las misiones jesuíticas en Oriente.

(4) «Historia de Guzman en dos tomos»

GUZMAN, Luis de: Historia de las misiones que han hecho los religiosos de la Compañia de Jesus, para predicar el Sancto Evangelio en la India Oriental y en los Reinos de la China y Japon. Alcala de Henares. Viuda de Juan Gracian, $1601^{109}$.

Sirva como colofón al repaso de biografias beatas la exaltación de los santos de la Compañía.

(145) «Vida de San Francisco de Borja»

NIEREMBERG, Juan Eusebio: Vida del Santo Padre y gran siervo de Dios el Beato Francisco de Borja. Tercero General de la Compañia de Jesus y antes duque quarto de Gandia. Van añadidas sus obras, que no estavan impressas antes. Madrid. María de Quiñones, 1644.

(184) «Fiestas de San Ygnacio de la junta de Biscaya»

Fray Gonzalo de Illescas, monje benedictino del monasterio de Dueñas (Palencia), comenzó la Historia Pontifical, que sería continuada después por otros dos autores hasta alcanzar cinco partes.

\footnotetext{
${ }^{109}$ Hay varias obras que se ajustan al apellido y al título, pero esta es la única en dos tomos y por su interés la consideramos la más probable.

"CUADERNOS DE ESTUDIOS GALLEGOS", Tomo XLII, Fascículo 107, Santiago 1995.
} 
(164) «Historia pontifical, tres tomos»

ILLESCAS, Gonzalo de: Primera parte de la Historia Pontifical y Catolica. Madrid. Melchor Sánchez, 1652.

BAVIA, Luis: Tercera [y Quarta] Parte dela Historia Pontifical y Catolica. Melchor Sánchez, 1652.

GUADALAJA Y JAVIER, Marcos: Quinta parte de la Historia Pontifical. Madrid. Viuda de Luis Sánchez, 1630.

(165) «Pineda: Monarchia eclesiastica»

PINEDA, fray Juan de: Los ocho libros de la primera parte de la Monarquia Eclesiastica. Zaragoza. Gabriel Dixar, 1576.

El tratado de Diego de Zúñiga inaugura las publicaciones de tipo teológico, respecto de las cuales no sucede lo que cabría quizás esperarse a priori, puesto que sus fechas de publicación no se circunscriben a los tiempos de los canónigos Mondragón.

(149) «Diego Estuniga. Sobre las eregias»

STUNICA, Didacus: Didaci Stunicae vera religiones in omnes sui temporis Hareticos. Libri tres, Salamanticae. Mathius Gastius, 1577. (196) «Sequeiro, Contra el clero galiciano»

SEQUEIROS Y SOTOMAYOR, fray Francisco: Eurithmia Pontificalis adversus Euroclydam cleri gallicani de ecclesiastica potestate declarationem. Alcalá de Henares. Francisco García, 1683.

(51) «Proposiciones condenadas»

LUMBIER, fray Raimundo: Noticia de las sesenta y cinco proposiciones nuevamente condenadas por N.S.S. Padre Inocencio IX, mediante su decreto de 2 de mayo de 1679... Setima impresion, añadidas las quarenta y cinco proposiciones de Alejandro VII. Lisboa. Domingos Carneiro, 1683.

Por lo que se ve, la preocupación por la ortodoxia parece haber estado claramente entre las preocupaciones de don Andrés. Para terminar con la temática religiosa hemos de volver a referirnos a la corriente prudencialista. Hemos visto como la búsqueda del recto camino era auxiliada en lo político por sesudos autores, y acabamos de ver como se prevenía de la heregía, pero es sin duda el fuero íntimo el principal responsable de que el rumbo no se extravíe. Los tratados tendentes a asegurarlo no escaseaban y garantizaban a aquellos que lo siguiesen la imitación de los santos y ejemplares varones y mujeres que hemos visto discurrir ante nosotros en sus biogra- 
fías. El ejercer como guía en el peregrinaje por el llamado itinerarium mentis ad Deum fue la tarea que se marcó la brillante literatura espiritual peninsular de la época, apoyándose sobre sus dos vértices, la ascética, que procuraba el autodominio y la purificación mediante la práctica de las virtudes y la ruptura con el pecado, y la mística, experiencia directa de la esencia divina. En la prosecución de este camino, estructurado en tres etapas (purgativa, iluminativa y unitiva), las diferentes órdenes religiosas adoptaron criterios doctrinales diversos, aunque complementarios. Así, Cristobal Cuevas $^{110}$, distingue cuatro tipos de misticismo en relación con ellas: afectivista (franciscanos), intelectualista (dominicos y jesuitas), ecléctico (carmelitas y agustinos) y ya por último heterodoxo (quietistas, panteístas e iluminados). De la quincena de autores que podríamos considerar como más relevantes en este tipo de literatura, hemos visto ya la presencia de santa Teresa y fray Luis de Granada, y deberíamos seleccionar de los anaqueles de don Andrés para colocarlo junto a ellos a Bernardino de Laredo, pero se echan en falta figuras tan agregias como san Ignacio de Loyola, san Pedro de Alcántara, san Juan de la Cruz o fray Luis de León ${ }^{111}$.

El amor divino era sin duda el móvil y el sustento que debía llevar el cristiano a guiar sus pasos hacia Dios, tal como consideraba el agustino español Fonseca (m. 1621), famoso predicador elogiado por Lope, Cervantes y Vicente Espinel

(50) «Fonseca: Del amor de Dios»

FONSECA, Cristobal: Tratado del Amor de Dios. Salamanca. Guillermo Foquel, $1592^{112}$.

El sendero precisaba ser iluminado para que sus lindes estuviesen claras, motivo por el cual el capuchino Gaspar de Viana escribió

(12) «Luz Clarisima de Biana»

VIANA, Gaspar de: Luz clarisima, que desengaña, mueve, guia y aficiona las almas que aspiran a la perfeccion y las lleva por el camino

\footnotetext{
${ }^{110}$ Historia y Crítica de la Literatura española. Ed. López Estrada, Francisco. vol. II. El Renacimiento. Barcelona. Ed. Crítica, 1980. CUEVAS, Cristóbal: Santa Teresa, San Juan de la Cruz y la literatura espiritual. pp. 490-491.

$" 11$ Cuevas incluye además los nombres de Francisco de Osuna, Juan de los Ángeles, Diego de Estella, Alonso de Orozco, Pedro Malón de Chaide y Juan de Ávila.

${ }^{112}$ Varias veces reeditada, la más cercana es la de Madrid. Luis Sánchez, 1620.
} 
mas solido y seguro a la union con Dios. Madrid. Domingo García Morras, 1661.

Pero no era este un peregrinar sencillo, pues esas veredas estaban pobladas de falaces asechanzas que había que distinguir, tal como ayudabà a desenmascarar el jesuita español Antonio de Castro

(193) «Castro: Fisonomia de la virtud»

CASTRO, Antonio de: Fisonomia de la virtud y del vicio al natural, sin colores, ni artificios. Valladolid. Joseph Rueda, 1676.

Este penoso transcurrir por el mundo, contaba por fortuna con una orientación suprema, la huella dejada por Cristo a su paso por él. Era este rastro el que se nos muestra en un verdadero clásico de la literatura espiritual española del siglo XVI nacido de la pluma del franciscano y médico sevillano Bernardino de Laredo (1482-1545)

(194) «Subida al monte Sion»

LAREDO, Bernardino de: Subida al Monte Sion por la via contemplativa. Contiene el conocimiento nuestro y el seguimiento de Cristo y el reverenciar a Dios en la contemplación quieta. Compilado en un convento de frailes menores. Sevilla. Juan Croberger, $1535^{113}$.

El jesuita vallisoletano Luis de la Puente (1574-1624), dedicó toda su vida a la dirección espiritual, siendo la primera plasmación de ello sus Meditaciones, que alcanzaron tres ediciones más en vida del autor, siendo traducidas con el paso del tiempo a numerosos idiomas ${ }^{114}$.

(115) «Meditaciones del Padre Luis de la Puente, dos tomos» PUENTE, Luis: Meditaciones de los mysterios de Nuestra Santa Fe con la practica de la oracion mental sobre ellos. Valladolid, 1605.

En medio de esa meditación y esfuerzo por seguir a Cristo, las fuerzas flaqueaban a veces ante las pruebas por la que se atravesaba y el alma necesitaba de consuelo

${ }^{113}$ PALAU. Op. cit. vol. XXII. p. 266-267. La edición más próxima es la de Alcalá de Henares, Juan Gracián, 1617.

${ }^{114}$ Valladolid 1607 y 1613 y Barcelona, 1613. Fue traducida al alemán, árabe, bohemio, francés, inglés, italiano, latín, polaco y portugués.

"CUADERNOS DE ESTUDIOS GALLEGOS", Tomo XLII, Fasciculo 107, Santiago 1995. 
(160) «Espejo de consolacion»

DUEÑAS, Juan: Primera [-Sexta] Parte del Espejo de consolación de tristes. Toledo. Pedro Rodríguez, 1591.

La paciencia era arma primordial en esa búsqueda de la paz interior. El agustino andaluz Zárate, maestro de teología en la universidad de Osuna y fino estilista entre los escritores ascéticos, reunió parte de sus sermones para ofrecerlos al lector necesitado de consejo.

(122) «Obras de Zarate»

ZARATE, Fernando de: Discursos de la paciencia christiana. Alcalá de Henares. Juan Iñíguez Lequerica, 1592. (2 vols.).

Recreando el alma en preocupaciones transcendentes y ejercitándola estrictamente, el fiel se hallaba preparado para acercarse al altar de la misa y entrar en comunión con su Salvador.

(125) «Silba espiritual»

ALVAREZ DE BENAVENTE, Antonio: Primera parte de la Sylva Espiritual de varias consideraciones para entretenimiento del alma christiana. Zaragoza. Lorenzo Robles, 1540.

Es aquí donde más valiosa se torna la privilegiada experiencia ignaciana de los miembros de la compañía, plasmada en la producción del vallisoletano Alonso Rodríguez (1538-1621), profusamente editada y traducida a las lenguas principales.

(45) «Exercicios de Rodriguez, en um tomo»

RODRIGUEZ, Alonso: Exercicios de perfeccion y virtudes cristianas.

Sevilla. Matías Clavijo, $1609^{115}$.

(185) «Sicardo: Sobre la comunion»

SICARDO, Juan Bautista: Breve resumen de la disposicion, reverencia y pureza con que deven llegar los fieles a recibir el Santisimo Sacramento del Altar. Alcalá de Henares. Nicolás De Xamares, $1673^{116}$.

${ }^{115}$ PALAU. vol. VI. p. 309. La primera edición se hizo en tres volúmenes. La única en un tomo es la de Barcelona, 1695.

${ }^{116}$ El agustino madrileño Juan Bautista Sicardo (1637-1717), rector de su orden para la provincia de Castilla, escribió además el curioso tratado Contra el escotado y profanidad de los trajes de las mujeres. Madrid, 1677.

"CUADERNOS DE ESTUDIOS GALLEGOS", Tomo XLII, Fascículo 107, Santiago 1995. 
Hecho todo lo cual no quedaba sino recrearse en la esperanza de la vida futura, acompañando en ello a Martín de Roa s.j. ${ }^{117}$

(39) «Roa: De los estados»

ROA, Martín de: Del estado de los bienaventurados en el cielo, de los niños en el limbo... Sevilla. G. Ramos Vejerano, 1624.

Sin abandonar la Compañía, hemos de citar a uno de sus miembros más leídos, cuyas obras fueron en su tiempo profusamente reeditadas, si bien la mayor parte han resistido mal el paso del tiempo.

(171) «Eusebio tres tomos espirituales»

NIEREMBERG, Juan Eusebio: Obras christianas. Domingo García y Morras, 1651. (3 vols. $)^{118}$.

El último personaje al que haremos referencia bien pudo ser modelo de virtudes para el arzobispo compostelano fray Antonio de Monroy, pues ostentó el cargo de obispo de Puebla de los Angeles durante su juventud, en el virreinato de Nueva España, de donde era natural el primero. Nos estamos refiriendo al navarro Juan de Palafox (1600-1659), conocido fundamentalmente por su pleito con los jesuitas, pero que fue, sin embargo, entusiasta promotor de programas arquitectónicos, como prueba que bajo su pontificado se terminasen las obras de la catedral de esa ciudad mexicana, empezadas hacía cien años y los edificios del palacio episcopal y del seminario, además de las cuarenta iglesias que se erigieron en su diócesis. Su fecundidad como escritor corrió pareja a su iniciativa en todos los demás campos en los que se movió.

(170) «Obras de Palafox, nuebe tomos»

PALAFOX Y MENDOZA, Juan de: Obras. Madrid. Pablo del Val, M. Alegre, María de Quiñones y Bernardo de Villadiego, 1659 a 1671. (8 vols.).

- Vida del venerable Palafox. Madrid, 1666.

${ }^{117}$ Martín de Roa, (1561-1637) pasó su vida entre las cátedras de gramática, retórica y humanidades de los colegios de Jerez, Écija, Sevilla, Málaga y Córdoba, que regentó y los cargos de gobierno de la Compañía.

${ }^{118}$ Los tomos II y III se titulan Obras espirituales.

"CUAdERnOS DE ESTUdiOS GALLEGOS", Tomo XLII, Fascículo 107, Santiago 1995. 
Cerraremos definitivamente el apartado religioso con las seis obras que no hemos logrado identificar. La primera tomos parece ser un libro litúrgico.

(116) «Un tomo latino de Divinis Officys».

(147) «Consejo del pacente, un tomo»

(184) «Verdadera amistad cristiana»

(14) «fray Pedro Maroja, un tomo»

(117) «Bida debota de Salas y (118) dos tomos de cartas»

Por último mencionar dos títulos de correspondencia algo dudosa.

(126) «Garcia de Loaysa Yncantica»

ALBA Y ASTORGA, fray Pedro de: Nova litteralis cantici magnificat expositio. Madrid. Francisco Nieto Salcedo, $1656^{119}$.

(191) «Quaresma antigua en latin»

GUERRA Y RIBERA, fray Manuel: Cuaresma continua. Madrid. D. Martínez Abad. 1699.

Viajemos ahora del mundo de las letras sacras al de las profanas, cruzando por el comunmente transitado puente de los autores antiguos. Sin ser ni mucho menos abultada la presencia los clásicos greco latinos, hay que reconocer en cambio que todos ellos pertenecen a la esencia de lo mejor que a la literatura universal dieron aquellos siglos. Comencemos por los tres poetas de la Edad de Oro.

(188) «Virgilio en romance»

VIRGILIO MARON, Publio. La Eneida de Virgilio, principe de los poetas latinos, traduzida en octava y verso castellano por Gregorio Hernandez de Velasco. Toledo. Diego de Ayala, 1577.

(175) «Oracio en un tomo»

HORACIO FLACCO, Quinto: Horacio español, esto es obras de $Q$.

Horacio Flacco, traduzidas en prosa española e ilustradas con argumentos, Epitomes y Notas en el mismo idioma. Parte Primera. Poesias liricas por el R.P. Urbano Campos. León. Anisson y Posuel, $1682^{120}$.

${ }^{119}$ Fray Juan García de Loaisa era el pseudónimo de fray Pedro de la Concepción, carmelita descalzo, cuyo nombre como seglar era Pedro de Alba y Astorga.

${ }^{120}$ Según Palau, Op. cit.: «A pesar de ser una traducción mediocre y de contener notas muy pobres, la obra del P. Campos fue refundida por el P. Luis Mínguez y estuvo de texto más de un siglo en las escuelas españolas»».

"CUADERNOS DE ESTUDIOS GALLEGOS", Tomo XLII, Fascículo 107, Santiago 1995. 
(62) «Obidio en romance»

OVIDIO NASON, Publio: Las Metamorphosis o transformaciones del excelente Poeta Ovidio en quinze libros buelto en castellano. Madrid. Domingo Morras, $1664^{121}$.

Aunque es bien sabido, hemos de recordar que estas obras de franqueaban la puerta hacia el mundo de la mitología, sobre todo en los casos de Virgilio y Ovidio, pero también al del arte de la poesía (Ars poetica) e incluso hacia la vida política del siglo I a.C. (Odas). La capacidad para orientarse con soltura entre el dédalo de fábulas mitológicas que nos ha transmitido la mitología clásica no era cuestión baladí para un cortesano del siglo XVII, puesto que el rico mundo de imágenes simbólicas que generaron en torno a sí los tratados de iconología de Alciato, Ripa o Covarrubias, e incluso las alegorías políticas de Saavedra y Fajardo bebían directamente en estas fuentes. Por lo tanto, la capacidad para interpretarlas cuando por ejemplo servían de motivo en un certamen literario o sus representaciones pictóricas adornaban las arquitecturas efímeras construidas con motivo de una celebración pública, evidenciaba la agudeza de ingenio de cada quien.

Los cuatro autores siguientes están en estrecha relación con la filosofia política que reinaba en el ambiente durante la segunda mitad del siglo XVII al que en parte ya nos hemos referido anteriormente. La Historia de Tucídides, familiar a los escolares e universitarios españoles desde el siglo XVI, ha sido tomada por muchos como un manual de ciencia política, si bien sobre ello no existe unanimidad ${ }^{122}$. Las pretensiones de Gracián Alderete respecto a su traducción, en cambio, parecen quedar muy claras en el acompañamiento que hace del título.

(9) «Historia de Suecidides»

TUCIDIDES: Historia de Thucydides. Que trata de las guerras entre los Peloponeses y Atheniense. La qual allende de las grandes y nota-

${ }^{121} \mathrm{O}$ tal vez: Libro de Metamorphoseos y fabulas del excelente poeta y philosopho Ovidio, noble cavallero Patricio romano. Traduzido de latin en romance. Salamanca, 1542.

${ }^{122}$ TUCIDIDES: Historia de la Guerra del Peloponeso. Madrid. Cátedra, 1988. Edición e introducción de Francisco Romero Cruz. p. 38. Durante este siglo son frecuentes las precisiones al momento y grados en lo que debía de abordarse su estudio, especialmente en los colegios jesuíticos.

"CUADERNOS DE ESTUDIOS GALLEGOS", Tomo XLII, Fascículo 107, Santiago 1995. 
bles hazañas por mar y tierra, de los unos y de los otros, y sus aliados y confederados, esta llena de oraciones y razonamientos prudentes y avisados a proposito de paz y de guerra. Traduzida... por el secretario Diego Gracian Alderete. Salamanca. Juan Canova, $1564^{123}$.

El didactismo no es el único rasgo en común entre la historiografía del ateniense y la de Tácito, puesto que ambos participan por una notable capacidad de profundización psicológica, tanto individual como colectiva. Según la perspectiva de la época la Historia y la Política son dos caras de una misma realidad, pues la primera es maestra de la segunda, concentrándose sus enseñanzas en las lapidarias sentencias tan propias de la obra tacitiana. Como señala Rayo Grauss, en la introducción a la obra de Alamos Barrientos se expone una concepción de la política como fruto de la experiencia humana, en un sentido, por tanto, radicalmente moderno y opuesto al sentido aristotélico de ciencia ${ }^{124}$.

(27) «Obras de Tasito en un tomo»

TACITO, Cayo Cornelio: Tacito Español ilustrado con Aforismos por Baltasar Alamos Barrientos. Madrid. Luis Sánchez, 1614 $4^{125}$.

Séneca era el complemento perfecto de Tácito, pues con su sentido ético servía de prevención ante la posible caída del gobernante en actitudes de cinismo radical afines a las teorías de Maquiavelo. Su papel como educador y privado de Nerón captó la atención de Quevedo y de Gracián.

(25) «Tragedia de Seneca, un tomo»

SENECA, Lucio Anneo: Tragoedia. Amsterdam. Typ. Sanzohiaam, $1695^{126}$.

${ }^{123}$ PALAU. Op. cit. vol. XXIV. p. 197. No hay más traducciones ni más ediciones hasta el siglo XIX, a pesar de que esta versión adolecía de graves defectos de interpretación tal como critica MENÉNDEZ PELAYO, Marcelino: Biblioteca de traductores españoles. Madrid. CSIC, 1952. vol. II. p. 188.

${ }^{124}$ RAYO GRAUS, A. Op. cit. p. 74.

${ }^{125}$ También podría tratarse de la traducción de Sueiro: Las obras de Cayo Cornelio Tacito. Traducidas de latin en castellano por Emanuel Sueyro, natural de la ciudad de Anvers. Amberes. Herederos de Pedro Bellero, 1613. Según PALAU. Op. cit. vol. XXII. pp. 374-375, era inferior a la de Alamos Barrientos.

${ }^{126}$ Las ediciones son muy numerosas. Citamos la más próxima a 1709. PALAU. Op. cit. vol. VI. pp. 492-493

"CUADERNOS DE ESTUdios GALlEGOS", Tomo XLII, Fascículo 107, Santiago 1995. 
La relación de Plinio el menor con Tácito no se cifra sólo en la buena amistad que les unió, por el contrario su Panegirico, es además de muestra de su refinada oratoria, documento ilustrativo del buen gobierno de uno de los más excelentes emperadores, hispánico por ende, en contraste con las perversas cualidades de Domiciano, sañudo perseguidor de los cristianos.

(46) «Plinio, dos thomos»

PLINIO, Gayo: El emperador politico y politica de emperadores. Vida del Emperador Ulpio Trajano sacada del Panegirico de Plinio Menor. Barcelona. J. Llopis, 1700 (2 vols. $)^{127}$.

La obra de más oscura identificación ha sido para nosotros

(152) «Sarrecinorum yn comedias platinas»

A pesar de que, como indicamos, a lo que parece don Andrés no dominaba el latín y menos aún el griego o quizás precisamente por eso, disponía de dos vocabularios que le ayudaban a salvar esa dificiencia.

(137) «Bocabulario trilingue»

CORREAS, Gonzalo: Trilingue de las tres lenguas Castellana, Latina $i$ Griega, todas en romance. Salamanca. Antonia Ramírez, 1627

(187) «Thesauro de Salas»

SALAS, Pedro de: Thesauros Hispano-Latinus. Valladolid. Juan Godínez de Milla, 1618.

Incluyamos por afinidad en el capítulo de diccionarios este método para aprender francés...

(91) «Arte de ablar frances»

P. B.: Arte para aprender facilmente y en poco tiempo a leer, escribir y hablar la lengua Francesa. Lyon. s. imp. 1672.

Los cimientos de la literatura española del Siglo de Oro, según quisieron sus protagonistas, estaban en buena medida en el mundo clásico grecolatino. No hay duda de que, en cuanto a ella, estos se hallaban bien asenta-

${ }^{127}$ Es la única edición en dos tomos tanto de Plinio el mayor como de su sobrino.

"CUADERNOS DE ESTUdIOS GALLEGOS", Tomo XLII, Fascículo I07, Santiago 1995 
dos, porque entre la colección de poetas, novelistas y dramaturgos con los que se deleitaba nuestro aristócrata se encuentra lo mejor que España aportó por entonces a la república literaria.

Tirso, por ser el decano, inaugura nuestra relación con su Deleitar aprovechando, que, como es sabido, recoge en su interior varias piezas teatrales y narraciones piadosas

(69) «Deleytar aprobechando»

MOLINA, Tirso de: Deleytar aprovechando. Madrid. Imprenta Real, $1635^{128}$.

El autor del Burlador de Sevilla, no podría ir seguido de otro que no fuese el patriarca de la escena española, don Pedro Calderón.

(107) «Calderón. Comedias, onze thomos»

CALDERON DE LA BARCA, Pedro: Comedias publicadas por Jose Calderon de la barca. Madrid, 1636-1677. (5 vols.).

- Comedias que nuevamente corregidas publica Don Juan de Vera Tarsis y Villarroel. Madrid. Francisco Sanz, 1682.

(102) «Autos de Calderon»

- Autos sacramentales, alegoricos y historiales. Primera parte. Madrid. Joseph Fernandez de Buendia. 1677.

Al sacerdote Antonio de Solís lo hemos encontrado ya cuando presentamos su obra acerca de la conquista de México y volveremos sobre él más adelante a propósito de su obra poética, pero aquí lo traemos a propósito de sus comedias, e inmediatamente a continuación de su amigo Calderón, con quien colaboró en la escritura de algunas piezas.

(120) «Solis, un tomo de comedias»

SOLIS Y RIVADENEIRA, Antonio: Comedias. Madrid. Melchor Alvarez, 1681.

${ }^{128}$ Además de tres autos sacramentales (El colmenero divino, No le arriendo la ganancia y Los hermanos parecidos), contiene una novela histórica (El bandolero), sobre la conversión de San Pedro Armengol.

"CUADERNOS DE ESTUdIOS GALLEGOS", Tomo XLII, Fascículo 107, Santiago 1995 
Exactamente de su misma edad, el infortunado Zabaleta (1610-1670), acusó también la influencia calderoniana, y de la misma forma que Solís no se ciñó exclusivamente al campo de la escena, sino que se internó en el campo de la didáctiva.

(11) «Obras de Zabaleta»

ZABALETA, Juan de: Obras en prosa de Don Juan de Zavaleta, cronista del Rey, por el mismo añadidas y por el dedicadas al Conde de Villaumbrosa. Madrid. Andrés García de la Iglesia, $1667^{129}$.

Sin dejar la escuela calderoniana, viene a nuestro encuentro un autor que debía complacer en sobremanera a don Andrés, ya que se hizo con sus obras completas, y no es para menos, porque Moreto y su Lindo Don Diego, siguen hoy mereciendo los aplausos del público y despertando las risas tanto como el Don Gil de Tirso

(101) «Moreto, tres tomos de comedias»

MORETO Y CABANA, Agustín: Primera parte de las comedias de Don Agustin Moreto. Valencia. Benito Macé, 1676.

- Segunda parte de las comedias de Don Agustin Moreto. Valencia. Bentio Macé, 1676.

- Tercera parte de las comedias de Don Agustin Moreto. Valencia. Benito Macé. $1681^{130}$.

Cierra el cortejo de dramaturgos el más joven de todos ellos, que no es otro que el atrabiliario bachiller Diamante, también con sus correspondientes tomos de comedias.

(100) «Diamante, Comedias, dos tomos»

DIAMANTE, Juan Bautista: Comedias. Madrid. Andrés García de la Iglesia, 1674 (2 vols.).

\footnotetext{
${ }^{129}$ Edición más próxima es la de Barcelona, Joseph Texido, 1704. Comprende: Theatro del hombre e historia y vida del conde Matisco, Historia de Nuestra Señora de Madrid. Favores milagrosos de esta Santa Imagen, Problemas de Filosofia natural, Errores celebrados en la antigüedad, Milagros de los trabajos, Día de fiesta por la mañana, Día de fiesta por la tarde, El emperador Herodiano.

${ }^{130}$ Edición más próxima es la del año 1703 por el mismo impresor.

"CUADERNOS DE ESTUDIOS GALLEGOS", Tomo XLII, Fascículo 107, Santiago 1995.
} 
El menos claro que esta serie es un volumen que se recoge con el escueto epígrafe de Entremeses. Pese a que en un primer momento pueda parecer que se trata de los escritos por Cervantes, entendemos como más probable que fuese alguno de los tres volúmenes que recogemos a continuación, porque la última edición de los Entremeses cervantinos anterior a 1709 se nos antoja ya muy lejana y su título completo varia demasiado respecto al asiento del escribano ${ }^{131}$. Con todo, después de las arbitrariedades que llevamos vistas, dar el paseo de la conjetura a la certeza resultaría cuando menos arriesgado.

(58) «Entremeses, un tomo»

- Entremeses, nuevos de diversos autores. Zaragoza. Pedro Lanaja y Lamarca, 1640.

- Entremeses. Alcalá. Francisco Ropero, 1643.

- Entremeses varios, aora nuevamente recogidos de los mejores ingenios de España. Zaragoza. Herederos de Diego Dormer, finales de s. XVII ${ }^{132}$.

Del teatro la novela, ninguna mejor que la primera de todas para hacer esta mudanza, que no necesita comentarse porque su título se basta

(55) «Don Quijote, dos tomos» ${ }^{133}$.

Viene don Alonso Quijano con séquito de pícaros, los unos de más ilustre autor como Marcos de Obregón.

(59) «Vida de Obregon»

ESPINEL, Vicente: Vida del escudero Marcos de Obregón. Madrid. Juan de la Cuesta, $1618^{134}$.

${ }^{131}$ Ocho comedias y ocho entremeses nuevos, nunca representados. Madrid. Viuda de Alonso Martín, 1615.

${ }^{132}$ Según PALAU. Op. cit. vol. 2. p. 187, no se editaron más libros con este título en los siglos XVI y XVIII.

${ }^{133}$ Resulta imposible decidirse por ninguna de las varias ediciones en dos tomos que se hicieron antes de 1709. La primera ilustrada en dos volúmenes es la de Madrid. Andrés García de la Iglesia, 1674.

${ }^{134}$ La última edición del siglo XVII reseñada por PALAU. Op. cit. vol. 3. pp. 147148, es la de Sevilla. Pedro de Pastrana, 1641.

"CUADERNOS DE ESTUDIOS GALLEGOS", Tomo XLII, Fascículo 107, Santiago 1995. 
los otros de más bellaco,

(60) «Estevanillo Gonzales»

GONZALEZ, Estebanillo: La vida y hechos de... Hombre de buen humor. Compuesto por el mesmo. Amberes. Viuda de Juan Cnobart, $1646^{135}$.

teniendo por último eslabón de su estirpe al quizás menos inspirado de todos, aunque no por eso menos popular y bien recibido en su momento.

(35) «Periquillo el gallinero»

SANTOS, Francisco: Periquillo el de las Gallineras. Madrid. Bernardo de Villa-Diego, $1668^{136}$.

Antes que a Montalbán (1602-1638), convendría citar a su más acérrimo enemigo, pero como ya hemos mencionado más arriba a don Francisco de Quevedo, baste aquí acordarnos de su Buscón, por hallarnos en el campo de la novela. Así pues, pasemos a su contrario, de quien curiosamente no encontramos ninguna de sus sesenta comedias

(53) «El Paratodos de Monte Alban»

PEREZ DE MONTALBAN, Juan: Para todos. Exemplos morales humanos y divinos. En que se tratan diversas ciencias, materias y facultades. Repartidas en los siete dias de la semana. Madrid. Imprenta del Reino, $1632^{137}$.

(20) «Novelas de Monte Alban»

- Sucesso y prodigios de amor. En ocho novelas. Añadido el Orfeo.

Zaragoza. Juan de Ibar, $1665^{138}$.

\footnotetext{
${ }^{135}$ Edición más cercana es la de Madrid. Melchor Sánchez, 1655.

${ }^{136}$ Francisco Santos nació y murió en Madrid (1623-1698).

${ }^{137}$ La edición más cercana es la de Lisboa. Domingo Carnero, 1692. Recuérdese las demoledoras décimas de Quevedo contra esta obra, que comienzan: «El licenciado libruno/ dicen que por varios modos/hizo un libro Para todos/no siendo para ninguno/Al principio es importuno/a la postre es almanaque,/baturrillo y badulaque; $\mathrm{Y}$ así supulico al poeta/que en el libro no meta/y si me metió, me saque./ Oh doctor, tu Para todos,/ entre el engrudo y la cola,/ es juego de perinola,/ digno de otro mil apodos...» QUEVEDO, Francisco de: Poesia original completa. Barcelona. Planeta, 1981. p. 1191.

${ }^{138}$ La más cercana edición es la de Cádiz. Alférez Bartolomé Núñez de Castro, 1682.

"CUADERNOS DE ESTUDIOS GALLEGOS", Tomo XLII, Fascículo 107, Santiago 1995.
} 
Aún cambiando de escritor, entremedias se nos cuela don Juan Pérez, pues una de sus novelas se imprimió con la obra del sacerdote murciano Polo de Medina,

(30) «Bureo de las musas»

POLO DE MEDINA, Salvador Jacinto: Bureo de las musas y honesto entretenimiento para el ocio. Con una novela de Montalban. Zaragoza. Juan de Ibar, $1659^{139}$.

Excesivamente postergada se encuentran en nuestros días la granadina doña Mariana de Carvajal, cuyas Novelas y Saraos, agradaron a sus contemporáneos no menos que otros autores a quien hemos visto pasar ante nosotros

(127) «Doña Mariana de Saabedra. Noches entretenidas»

CARVAJAL Y SAAVEDRA, Mariana de: Navidades en Madrid y noches entretenidas, en ocho novelas. Madrid. Domingo García Morrás, 1663.

Hemos de reconocer que no hay más causa para preferir esta correspondencia a otras que el hecho de tratarse de la más moderna de todas las que hemos encontrado con este título ${ }^{140}$.

(38) «Historia de dos amantes»

CASTILLEJO, Cristóbal: Historia de los dos leales amadores Piramo y Tisbe. En la qual declara la grande fuerça que haze el amor, pues pierde su vida por el amado, como por esta obra se declara. Alcalá de Henares. Andrés Sánchez de Espeleta, 1615 ${ }^{141}$.

También nos plantea dudas la obra de Cristóbal Lozano, colección de novelas cortas con intención moralizante, debido al apellido con que se reseña al autor.

\footnotetext{
${ }^{139}$ Mucho menos probable, aunque no descartable, es que se tratase de MALAVENDA, Jacinto Alonso: El Bureo de las Musas del Turia. Valencia. Silvestre Esparza, 1629.

${ }^{140}$ Añadámos otras dos posibilidades: HELIODORO, Obispo de Tricca: La historia de los dos leales amantes Theagenes y Chariclea, Trasladada... de latin en romance por Fernando de Mena, vecino de Toledo. Alcalá de Henares. Juan Gracían, 1587. PICCOLOMINI, Eneas Silvio: Hystoria muy verdadera de dos amantes... Sevilla, Jacobo Croberger, 1512.

${ }^{141}$ CATALINA GARCÍA. Op. cit. p. 269.

"CUADERNOS DE ESTUDIOS GALLEGOS", Tomo XLII, Fascículo 107, Santiago 1995.
} 
(104) «Soledades de la vida de Gamarra»

LOZANO, Cristóbal: Soledades de la vida de desengaños del mundo. Madrid, $1667^{142}$.

Extraña la ausencia de Lope entre los dramaturgos, pero al fin lo hallamos presente entre los poetas, lo que si cabe nos muestra más exquisito el gusto de don Andrés

(23) «El pastor de Belen de Lope»

VEGA Y CARPIO, Lope: Pastores de Belen, prosas y versos divinos.

Madrid. Joan de la Cuesta, 1612.

(32) «Nocadia de Don Lope»

- Arcadia. Madrid. s. imp. 1598.

De Góngora se nos dice apenas que poseía un tomo que, al no figurar con un título completo, nos sugiere el que se tratase de una recopilación

(105) «Gongora, un tomo»

GONGORA Y ARGOTE, Luis: Todas las obras de Don... Sevilla. N. Rodríguez, $1648^{143}$.

Más próximo a Argensola que a Góngora, el príncipe de Esquilache (15821658 ) fue modelo de noble, de mecenas, de político y de literato. Nieto de San Francisco de Borja, virrey del Perú y gran promotor de las letras, fue poeta elegante y gran cultivador del romance

(66) «Obras de Esquilache, un tomo»

BORJA Y ARAGON, Francisco de: Las obras en verso. Madrid. Diego

Díaz de la Carrera, 1648.

Si Esquilache pudo ser espejo en el que se mirase nuestro marqués, lo mismo puede decirse del Conde de Rebolledo (1597-1676), embajador en Dinamarca entre 1648 y 1662, del cual vemos aquí la única edición contemporánea de la primera de sus Selvas ${ }^{144}$, un poema didáctico sobre el arte de la guerra.

\footnotetext{
${ }^{142}$ PALAU. Op. cit. vol. VI. p. 283.

${ }^{143}$ También resultaría verosímil de ser: Obras en verso del Homero español, que recogio Juan Lopez de Vicuña. Madrid. Viuda de Luis Sánchez, 1627.

${ }^{144}$ Fueron las otras dos Selvas dánicas y Selva Sagrada publicadas en Copenhague en 1655 y 1657 respectivamente.
}

"CUADERNOS DE ESTUDIOS GALLEGOS", Tomo XLII, Fascículo 107, Santiago 1995 
(93) «Silba militar de Rebolledo»

REBOLLEDO, Bernardino de: Selva militar y politica. Colonia. Antonio Kinchio, 1652.

El segoviano Enríquez Gómez (1600-1663), pasó buena parte de su vida en el exilio. Sirvió como secretario a Luis XIII y, a su regreso a España, acabó por ser víctima de la Inquisición por su origen judío. Sus Academias morales salieron a la luz acompañadas de cuatro comedias de corte calderoniano.

(103) «Academias morales

ENRIQUEZ GOMEZ, Antonio: Academias morales de las musas. Burdeos, $1642^{145}$.

De Antonio de Solís hemos hablado ẹn cuanto a su faceta de historiador y comediógrafo y ahora lo tenemos ante nosotros en su vertiente de poeta en una edición póstuma.

(131) «Solis. Poesias Varias»

SOLIS Y RIBADENEIRA, Antonio de: Varias poesias sagradas y profanas que dexo escritas (aunque no juntas ni retocadas) Don... Recogidas y dadas a la luz por Don Juan de Goyeneche. Madrid. Antonio Román, 1692.

La poesía sagrada floreció tanto de modo independiente como agrupada en torno a academias y certámenes consagrados a la alabanza de la divinidad y los santos y que aquí vemos convocados en honor de la Virgen. El primero de estos títulos procede de la pluma del jesuita gallego Luis Losada y Quiroga (1681-1748), poeta y fílósofo, que ejerció la docencia en el colegio de la orden de Salamanca

(192) «Certamen salimantino de Don Luis de Losada»

LOSADA, Luis de: Triunfos de la aurora: traslación de una imagen de la Virgen en Segovia y certamen que se celebro con este motivo. Salamanca, s. imp. ni fecha ${ }^{146}$.

(54) «Certamen de la Soledad»

${ }^{145}$ La primera edición española es la de Valencia. Claudio Macé, 1648 y la última la de Madrid. J. Fernández de Buendía, 1660.

${ }^{146}$ SIMÓN DIAAZ, José: Jesuitas de los siglos XVI y XVIII: escritos localizados. Madrid. Universidad Pontificia de Salamanca, 1975. p. 155. Lógicamente es anterior a 1709, pero por la edad del autor, tiene que ser posterior a 1700 .

"CUADERNOS DE ESTUdIOS GALLEGOS", Tomo XLII, Fascículo 107, Santiago 1995 
Valgan como conclusión estos dos volúmenes de variado carácter

(21) «Poesias de Pantaleon. Un tomo»

PANTALEON DE RIBERA, Anastasio: Obras. Madrid. Francisco Martínez, 1634.

(128) «Obras poeticas de un anonimo»

Agudo entre los agudos, la habilidad para la pulla de Quevedo no es sino la quintaesencia de una destreza que practicaban con pasión los españoles del siglo XVII. Excusemos aquí el mencionar de nuevo sus obras, pero muy al caso viene en cambio el traer la traslación de los epigramas de John Owen (1560-1622), que no podían hallar terreno mejor abonado para su éxito que aquel al que fueron transplantados por Francisco de la To$\operatorname{rre}^{147}$.

(112) «Agudezas de Oben»

OWEN, John: Agudezas, traduzidas en metro castellano, ilustradas con adiciones y notas por Don Francisco de la Torre. Madrid. Francisco Sanz, 1674.

- $2^{\mathrm{a}}$ parte. Madrid. Antonio González Reyes, 1682.

¿Sería esta obra compañera del siguiente volumen?

(153) «Comentarios sutiles para la platica»

Como quiera que sea, hemos de abandonar al fin las cosas del espíritu, de la literatura y de la alta política para ocuparnos de las del cuerpo, preciso de cuidados en la enfermedad y digno de los halagos del paladar. A la cirugía del castellano Fragoso, que se impone en los casos más desesperados

(162) «Fragoso: Cirujia unibersal»

FRAGOSO, Juan: Cirugia universal. Madrid. Gómez, $1581^{148}$.

acompañan la menos drástica farmacopea del bizantino Dioscórides,

${ }^{147}$ CHEVALIER, Maxime: Quevedo y su tiempo: la agudeza verbal. Barcelona. Crítica, 1992.

${ }^{148}$ PALAU. vol. III. p. 268. No se citan más ediciones.

"CUADERNOS DE ESTUDIOS GALlEGOS", Tomo XLIl, Fascículo 107, Santiago 1995. 
(8) «Laguna, sobre Dioscorides»

LAGUNA, Andrés de: Pedacio Dioscorides Anazarbeo, Acerca de la materia medicinal y de los venenos mortiferos. Traduzido de lengua Griega en la vulgar castellana, illustrado con claras y substanciales Annotationes y con las figuras de innumeras plantas exquisitas y raras, por el Doctor Andres de Laguna, Medico de Julio III Pontifice Maximo. Salamanca. Mathias Gast, $1566^{149}$.

y los remedios caseros del Don Alejo, en el que se entremezclan recetas de culinarias con pócimas salutíferas

(63) «Don Alexo, un tomo»

PIAMONTES, Alexo: Secretos del Reverendo Don Alexo Piamontes. Traduzidos de lengua italina en Castellana, añadidos y emendados en muchos lugares en esta ultima impresion. Alcalá de Henares. Antonio Vázquez, $1640^{150}$.

lo que nos conduce definitivamente a la cocina, en una correspondencia indeterminable, que dejamos abierta estas dos posibilidades

(61) «Arte de cocina»

MARTINEZ MOTIÑO, Francisco: Arte de Cozina, pasteleria, bizcocheria y Conserveria. Compuesto por Francisco Motiño, cocinero mayor del Rey nuestro Señor. Madrid. Luis Sánchez, 1611.

GRANADO, Diego: Libro del Arte de cozina, en el qual se contiene el modo de guisar de comer en qualquier tiempo, assi de carne, como de pescado, para sanos y enfermos y convalecientes, assi de pasteles, tortas y salsas, como de conservas a la usança Española, italiana y Tudesca de nuestros tiempos. Madrid. Luis Sánchez, $1599^{151}$.

Ya sólo nos resta citar aquellas obras que se han resistido a ser identificadas y que incluso en su tema resultan de clasificación oscura.

${ }^{149}$ PALAU. vol. III. p. 65. La primera edición se hizo en Amberes por Juan Latio en 1555, tras la cual siguieron muchas más, siendo la más próxima a 1709 la de Valencia, Macé, 1695.

${ }^{150}$ CATALINA GARCİA, Juan: Ensayo de una tipografia Complutense. Madrid. Manuel Tello, 1889. p. 301. n 976.

${ }^{\text {isl }}$ PÉREZ PASTOR. vol. 1. p. 332. n 627.

"CUADERNOS DE ESTUDIOS GALLEGOS", Tomo XLII, Fasciculo 107, Santiago 1995. 
(28) «Vigilia del sueño, un tomo», (29) «Soplos de la verdad», (34) «Anzuelo de las bolsas», (113) «Orden de vida», (123) «Las heridas de Bera», (183) «Alfabeto coronado», (57) «Monstibo de Grecia».

Tras esta prolija lista de títulos y autores, una agrupación temática nos ofrece los siguientes resultados:

\begin{tabular}{lcc}
\hline Temas & $\mathrm{n}^{\circ}$ volủmenes & \% sobre el total \\
\hline Genealogía y Órdenes militares & 9 & $3^{\prime} 22$ \\
Milicia & 1 & $0^{\prime} 35$ \\
Náutica & 1 & $0^{\prime} 35$ \\
Viajes & 9 & $3^{\prime} 22$ \\
Historia & 20 & $7^{\prime} 16$ \\
Tratados políticos & 13 & $4^{\prime} 65$ \\
Emblemática & 2 & $0^{\prime} 71$ \\
Derecho & 18 & $6^{\prime} 45$ \\
Religión & 130 & $46^{\prime} 60$ \\
$\quad$ Teología (4) & & \\
$\quad$ Filosofia moral (9) & & \\
$\quad$ Sagrada escritura (3) & & \\
$\quad$ Dres. de la Iglesia (1) & & \\
$\quad$ Mística y ascética (35) & & \\
$\quad$ Sermones (30) & & \\
$\quad$ Vidas de santos (25) & & \\
$\quad$ Historia de la Iglesia (14) & & \\
$\quad$ Otros (9) & & \\
Lengua y Literatura & & \\
$\quad$ Literatura moderna (57) & & \\
$\quad$ Clásicos latinos (9) & & \\
$\quad$ Gramáticas y diccionarios (3) & & $0^{\prime} 71$ \\
Medicina & & $0^{\prime} 71$ \\
Cocina \\
Buenas maneras \\
Indeterminados & 2 & $0^{\prime} 71$ \\
\hline TOTAL & 2 & \\
\hline & & \\
\hline
\end{tabular}

"CUADERNOS DE ESTUdIOS GALLEGOS", Tomo XLII, Fascículo 107, Santiago 1995. 
Como es habitual en las bibliotecas de la época los libros religiosos ocupan un porcentaje muy elevado, debido entre otros motivos a que la oferta que de ellos existía era mucho más rica que la del resto de las materias ${ }^{152}$. Con todo, en comparación con otros casos, en los que no suele superar una cuarta parte, se nos hace particularmente abultado este $45 \%$. Como hechos visto, sólo en una pequeña parte podría justificarse con el hecho de que la jefatura de la familia fuese ostentada durante largo tiempo por clérigos, puesto que muchos de los títulos de este capítulo fueron editados en vida de don Andrés o de su padre don Juan, lo que nos indica que bien pudo existir un sincero interés por estos asuntos. Tampoco debemos despreciar las preferencias de la marquesa doña Rosolea, nacida en una familia poseedora de una colosal biblioteca ${ }^{153}$. Las lecturas de las damas de la nobleza, orientadas con frecuencia por sus directores espirituales, se nutrían en buena medida de literatura de esta clase. Otro punto que ha de considerarse son las relaciones de los Mondragón con las diferentes órdenes religiosas, bien porque algunos de sus miembros profesasen en ellas, como es el caso por ejemplo de dos de los hermanos de don Juan, miembro uno de la Compañía de Jesús, y profesa otra en las benedictinas de San Paio, o bien por la patrocinio que recibían de su parte. Así, don Andrés guardaba una estrecha relación con la Orden de Predicadores ${ }^{154}$.

Un segundo gran grupo es el que acoge en su interior a todos aquellos libros que pudieron contribuir a ilustrar al marqués como noble, político y cortesano. Y, aquí, de cierto, han de tomarse en consideración el Derecho, la Política y la Historia, pero también los tratados genealógicos, de Milicia, Náutica, viajes, emblemas, e incluso los de Medicina y Cocina, que a menudo explicaban además de recetas, el modo en que debía de servirse la mesa. La suma de todos estos títulos supondría casi un $30 \%$.

Por fin, los libros de lenguas y literatura se agruparían para formar un $20 \%$. Es preciso recalcar una vez más lo infrecuente y excepcional de esta biblioteca, a propósito de estos volúmenes. Lo habitual entre los poseedores de libros que en esta época habitan Santiago y Galicia, es que sus

\footnotetext{
${ }^{152}$ Sobre la oferta disponible en las librerias de Santiago vid. GELABERT, Op. cit. pp.

${ }^{153}$ Véase el inventario postmorten de su hermano el almirante en FERNÁNDEZ DURO: El último almirante de Castilla. Madrid, 1903. pp. 103 y ss.gg.

${ }^{154}$ PARDO, fray Aureliano: La iglesia de Santo Domingo de Santiago. Cofradias en ella establecidas y sus cultos. Cuadernos de Estudios Gallegos. 1944-45. pp. 633-657.
} 150-154.

"CUADERNOS DE ESTUdIOS GALlEGOS", Tomo XLII, Fascículo 107, Santiago 1995. 
gustos literarios dejen mucho que desear de forma que, junto a los ejemplares que puedan considerarse profesionales en cada caso (Derecho, Religión, Arquitectura, etc.), tan sólo hallamos unos cuantos libros de entretenimiento escogidos entre los más populares y difundidos, por no decir entre los de más fácil lectura.

Con todo, como hemos visto a lo largo de estas líneas, el empleo de una clasificación estanca no deja de ser más que un medio que nos ayude a aclarar nuestras ideas en lo referente a los contenidos. Así por ejemplo, la obra de Tácito, la ordenamos junto a los demás clásicos latinos, pero está claro que las enseñanzas políticas que pudo deparar a sus lectores no han de perderse de vista.

El perfil de la biblioteca de don Andrés se integra a la perfección en la España de su tiempo. El interés por la religión, el derecho, la historia, la política, el prurito nobiliario, los asuntos de Italia, Portugal, Francia e Inglaterra, la preocupación por los acontecimientos militares, el práctico desinterés por las ciencias, hacen que encaje con un modelo mental que, en opinión de Benassar debió ser muy extenso en los grupos dominantes de la España de entonces ${ }^{155}$.

Sea como fuere, atinadas o no nuestras conclusiones, siempre podremos desandar nuestro camino para acudir en busca de fray Antonio de Guevara, y hacer decir con él a don Andrés «por manera que si mi cuerpo despedazen los gusanos, a lo menos hallarán mi coraçon entero en mis libros $\rangle^{156}$.

\section{ABREVIATURAS}

- A.D.S.: Arquivo Histórico Diocesano de Santiago.

- A.H.M.C.: Arquivo Histórico Municipal de A Coruña.

- A.H.U.S.: Arquivo Histórico da Universidade de Santiago.

- A.I.C.N.C.: Archivo del Ilustre Colegio Notarial de La Coruña.

- A.R.G.: Arquivo do Reino de Galicia.

${ }^{155}$ BENASSAR, Bartolomé: Los inventarios post-mortem y la Historia de las mentalidades. II Coloquio de Metodología aplicada. vol. II. Santiago. Universidad de Santiago, 1984. pp. 138-146.

156 Marco Aurelio.

"CUADERNOS DE ESTUdios GALlEGOS", Tomo XLII, Fascículo 107, Santiago 1995. 


\section{BIBLIOGRAFÍA}

ANEIROS RODRIGUEZ, R.M.: Aportación documental sobre la actividad compostelana entre 1550 y 1570. Universidad de Santiago, 1990. Tesis de licenciatura inédita.

BENASSAR, Bartolomé: Los inventarios post-mortem y la Historia de las mentalidades. II Coloquio de Metodología aplicada. vol. II. Santiago. Universidad de Santiago, 1984. pp. 138-146.

Biblioteca Nacional de Madrid: Catálogo general de libros impresos hasta 1981. Editado por Chadwych-Healey France. Microfichas.

The British Library General Catalogue of Printed Books to 1975 on CD ROM. Eton Winds, 1992.

BOUZA-BREY TRILLO, F.: E1 impresor compostelano del siglo XVII, Juan Guixard de León. Cuadernos de Estudios Gallegos. vol. XXI. Santiago, 1966.

BUSTAMANTE Y URRUTIA, J.M.: Catálogos de la Biblioteca Universitaria de Santiago. Santiago. Universidad de Santiago, 1948.

CARRO GARCÍA, A.J.: Fachada principal del palacio del Marqués de Santa Cruz de Santiago. Cuadernos de Estudios Gallegos. 1964, p. 320.

CATALINA GARCÍA, Juan: Ensayo de una tipografia complutense. Madrid. Manuel Tello. 1889.

CHEVALIER, M.: Lectura y lectores en la España de los siglos XVI y XVII. Madrid. Turner, 1976.

- Quevedo y su tiempo: la agudeza verbal. Barcelona. Crítica, 1992.

CRESPO DEL POZO, Fray José de Santiago: Blasones y linajes de Galicia. Tomo II.

CUEVAS, Cristóbal: Santa Teresa, San Juan de la Cruz y la literatura espiritual: En Historia y Crítica de la Literatura española. Ed. López

"CUADERNOS DE ESTUDIOS GALLEGOS", Tomo XLII, Fasciculo 107, Santiago 1995. 
Estrada, Francisco. vol. II. El Renacimiento. Barcelona. Ed. Crítica, 1980. pp. 490-491.

EGIDO, Aurora: Emblemática y literatura en el Siglo de Oro. Ephialte. Lecturas de Historia del Arte, 2. Vitoria, 1990.

FERNÁNDEZ DURO: El último almirante de Castilla. Madrid, 1903.

FERNÁNDEZ GASALLA, Leopoldo: El mecenazgo de la familia Mondragón. El pazo de Santa Cruz de Rivadulla. Abrente, La Coruña, 1991-92, nº 23-23.

- Las bibliotecas de los arquitectos gallegos en el siglo XVII: Los ejemplos de Francisco Dantas y Diego de Romay. Museo de Pontevedra. vol. XLIII [en prensa].

FOLGAR DE LA CALLE, M.C.: Un inventario de bienes de Fernando de Casas. Cuadernos de Estudios Gallegos. Santiago, 1982.

- Simón Rodríguez. A Coruña. Fundación Barrié de la Maza. 1989.

GÁNDARA, fray Felipe de la: Armas y Triunfos de los Hijos de Galicia. Santiago. Bibliófilos gallegos, 1970. Ed. facsímil.

GARCÍA GONZÁLEZ, Fernando: As bibliotecas particulares no Ferrol do Antigo Réxime (1680-1835). Historia Nova II. Santiago. Asociación Galega de Historiadores. 1994. pp. 107-118.

GARCÍA RUIZ, Víctor: Introducción a MORETO CAVANA, Agustín: El lindo don Diego. Madrid. Espasa Calpe, 1993.

GELABERT GONZÁLEZ, Juan Eloy: Santiago y la tierra de Santiago de 1500 a 1640. A Coruña. Ediciós do Castro, 1982.

- La cultura libresca en una ciudad de provincias del Renacimiento. II Coloquio de Metodología aplicada. vol. II. Santiago. Universidad de Santiago, 1984. pp. 147-153.

GIBERT, Rafael: Ciencia jurídica española. Granada. Imprenta de Francisco Román, 1982.

"CUADERNOS DE ESTUdIOS GALlegOS", Tomo XLII, Fascículo 107, Santiago 1995. 
GRAESSE, Jean George Théodore: Trésor de livres rares et précieux. Milán. G.G. Gorlich. 1950.

KAMEN, Henry: La España de Carlos II. Barcelona. Crítica. 1987.

LALINDE ABADIA, Jesús: Iniciación histórica al derecho español. Barcelona. Ariel, 1978.

LUCIO DE AZEVEDO, J.: História de António de Vieira. Lisboa. Classica Editora, 1992. 2 vols.

MARTÍN ABAD, Julián: La imprenta en Alcalá de Henares (1502-1600). Madrid. Arco. 1991.

MENÉNDEZ PELAYO, Marcelino: Biblioteca de traductores españoles. Madrid. CSIC, 1952.

PALAU Y DULCET, A.: Manual del librero hispanoamericano. Barcelona, 1950.

PARDO, fray Aureliano: La Iglesia de Santo Domingo de Santiago. Cofradías en ella establecidas y sus cultos. Cuadernos de Estudios Gallegos. 1944-45.

PAYNE, Stanley G.: La España imperial. Madrid. Globus Comunicación, 1994.

PÉREZ COSTANTI, P.: Diccionario de artistas que florecieron en Galicia en los siglos XVI y XVII. Santiago, 1930.

PÉREZ PASTOR, Cristóbal: Bibliografia madrileña. Madrid. Tipografia de los Huérfanos. 1891.

QUEVEDO, F. de: Poesía original completa. Barcelona. Planeta. 1981.

RALLO GRUSS, Asunción: La prosa didáctica en el siglo XVI. Madrid. Taurus. 1987.

- La prosa didáctica en el siglo XVII. Madrid. Taurus. 1988.

"CUADERNOS DE ESTUdiOS GALlEGOS", Tomo XLII, Fascículo 107, Santiago 1995. 
RÍOS MIRAMONTES, María Teresa: Estudio histórico artístico de la iglesia del Divino Salvador de Coiro. Patronazgo de los Mondragón, marqueses de Santa Cruz de Rivadulla. Estudios de Historia del Arte en honor del profesor Dr. D. Ramón Otero Túnez. Santiago. Universidad de Santiago. 1993. pp. 251-276.

SÁNCHEZ CANTÓN, Francisco Javier: Los libros españoles que poseyó Velázquez. En Varia Velazqueña. Madrid. 1960.

SEBASTIÁN, S.: Arte y humanismo. Madrid. 1981.

SEMPERE, Juan: Historia del derecho español. Madrid. Imprenta de González y Vicente. 1847.

SIMÓN DÍAZ, José: Impresos del siglo XVII. Madrid, 1972.

- Jesuitas de los siglos XVI y XVII: escritos localizados. Madrid. Universidad Pontificia de Salamanca. 1975.

STRADLING, R.A.: Felipe IV y el gobierno de España (1621-1665). Madrid. Cátedra. 1989.

TAÍN GUZMÁN, Miguel: Comentarios a Excelencias, Antigüedad y Nobleza de la Arquitectura. Santiago. Xunta de Galicia. 1993.

WARD, Philil. Ed.: Diccionario Oxford de literatura española e hispanoamericana. Barcelona. Crítica. 1984. 